\title{
Stress-induced tyrosine phosphorylation of RtcB modulates IRE1 activity and signaling outputs.
}

\begin{abstract}
Alexandra Papaioannou ${ }^{1,2}$, Federica G. Centonze ${ }^{1,2,13}$, Alice Metais ${ }^{1,2,13}$, Marion Maurel $^{1,2}$, Luc Negroni ${ }^{3,4,5}$, Matías Gonzalez-Quiroz ${ }^{1,6,7,8}$, Sayyed Jalil Mahdizadeh ${ }^{9}$, Gabriella Svensson $^{9}$, Ensieh Zare Golchesmeh ${ }^{9}$, Alice Blondel ${ }^{1,2}$, Albert C Koong ${ }^{10}$, Claudio Hetz ${ }^{6,7,8}$, Rémy Pedeux ${ }^{1,2}$, Michel L. Tremblay ${ }^{11,12}$, Leif A. Eriksson ${ }^{9,14}$, Eric Chevet $^{1,2,14}$
\end{abstract}

${ }^{1}$ INSERM U1242, University of Rennes, Rennes, France; ${ }^{2}$ Centre Eugène Marquis, Rennes, France; ${ }^{3}$ Centre National de la Recherche Scientifique, UMR7104, 67404 Illkirch, France. ${ }^{4}$ Institut National de la Santé et de la Recherche Médicale, U1258, 67404 Illkirch, France. ${ }^{5}$ Université de Strasbourg, 67404 Illkirch, France. ${ }^{6}$ Biomedical Neuroscience Institute (BNI), Faculty of Medicine, University of Chile, Santiago, Chile. ${ }^{7}$ Center for Geroscience, Brain Health and Metabolism (GERO), Santiago, Chile. ${ }^{8}$ Program of Cellular and Molecular Biology, Institute of Biomedical Sciences, University of Chile, Santiago, Chile. ${ }^{9}$ Department of Chemistry and Molecular Biology, University of Gothenburg, Göteborg, Sweden. ${ }^{10}$ Department of Radiation Oncology, The University of Texas MD Anderson Cancer Center, Houston, Texas. ${ }^{11}$ Goodman Cancer Research Centre, McGill University, Montreal, QC, Canada.

${ }^{12}$ Department of Biochemistry, McGill University, Montreal, QC, Canada.

Keywords: Endoplasmic Reticulum, UPR, XBP1s

Running title: Tyrosine phosphorylation-dependent regulation of XBP1 splicing

${ }^{13}$ These authors contributed equally to the work

${ }^{14}$ Correspondence to EC (eric.chevet@inserm.fr) or LAE (leif.eriksson@chem.gu.se) 


\section{Abstract}

The most evolutionary conserved sensor of the Unfolded Protein Response, IRE1, signals through its cytosolic kinase and endoribonuclease (RNase) activities. IRE1 RNase can either catalyze XBP1 mRNA unconventional splicing or degrade RNAs through Regulated IRE1-Dependent Decay (RIDD). The balance between these two activities controls cells' life and death decisions upon ER stress. The outputs of IRE1 RNase activity have been well documented, however, the mechanisms by which IRE1 triggers adaptive or death signals remain unclear. We hypothesized that XBP1 mRNA splicing and RIDD could be co-regulated by the IRE1 RNase regulatory network. We showed that the tRNA ligase RtcB which, together with IRE1, is responsible for XBP1 mRNA splicing, is tyrosine phosphorylated by c-Abl and dephosphorylated by PTP1B. We identified RtcB Y306 as a key residue which, when phosphorylated, perturbs RtcB interaction with IRE1, thereby attenuating XBP1 mRNA splicing and favoring RIDD. Our results demonstrate that the IRE1/RtcB signaling is controlled by tyrosine phosphorylation and that the nature of the stress determines cell adaptive or death outputs. 


\section{Introduction}

The imbalance between the cellular demand to fold secretory and transmembrane proteins and the Endoplasmic Reticulum (ER) capacity to achieve this function can result in the accumulation of improperly folded proteins in this compartment, a situation known as ER stress [1]. Activation of the ER stress sensors Inositol-Requiring Enzyme 1 alpha (referred to as IRE1 hereafter), Activating Transcription Factor 6 alpha (ATF6a) and Protein kinase RNA (PKR)-like ER kinase (PERK) aims to restore ER homeostasis and is known as the adaptive Unfolded Protein Response (UPR). However, when the stress cannot be resolved, the UPR triggers apoptosis, which is referred to as terminal UPR. Thus far, the mechanisms controlling the switch between adaptive and terminal UPR remain incompletely characterized. Among the possible candidates, the IRE1 pathway being greatly conserved through evolution, plays crucial roles in both physiological and pathological ER stress. Similar to the other sensors, IRE1 is an ER transmembrane protein activated after dissociation from Binding immunoglobin Protein (BiP) and/or direct binding to improperly folded proteins [2].

IRE1 is characterized by the presence of both kinase and endoribonuclease domains in its cytosolic region. After its dimerization/oligomerization, IRE1 transautophosphorylates, allowing the recruitment of TRAF2 and subsequent activation of the JNK pathway [3]. IRE1 dimerization and phosphorylation also yields a conformational change which activates its RNase domain and leads to unconventional splicing of the XBP1 mRNA and subsequent expression of a major UPR transcription factor XBP1s [4,5]. Importantly, the ligation following the IRE1mediated cleavage of the 26 nucleotide intron in the XBP1 mRNA is catalyzed by the tRNA ligase RtcB [6-9]. IRE1 RNase domain also promotes the cleavage of mRNA [10,11], rRNA [12] and miRNA [13,14] sequences, a process named Regulated IRE1Dependent Decay (RIDD) of RNA [10]. Interestingly, the degree of oligomerization of IRE1a may define its RNase activity towards XBP1 mRNA splicing or RIDD, ultimately impacting on cell fate [15-17]. Although the order of oligomerization required for XBP1 mRNA splicing vs. RIDD activity is still debated, there is a consensus on the cytoprotective effects of XBP1s and the cell death-inducing outputs of RIDD under acute ER stress [14-16]. RIDD was also described to maintain ER homeostasis under basal conditions [18]. In this model, while XBP1 mRNA splicing is 
induced during the adaptive UPR (aUPR) and inactivated during the terminal UPR (tUPR), RIDD displays an incremental activation pattern reaching unspecific RNA degradation during tUPR. Despite our knowledge on IRE1 signaling biological outputs, little is known on the integration of these two RNase signals and how their balance impacts on the life and death decisions of the cell. The existence of a multiprotein complex recruited in IRE1 foci that dynamically changes composition during the course of ER stress, named "UPRosome", has been suggested as a possible modulation mechanism $[19,20]$. This is supported by the recent identification of IRE1 interactors (e.g. PP2A and TUBa1a) regulating XBP1 mRNA splicing differently from RIDD [21].

Herein, we hypothesize that XBP1 mRNA splicing and RIDD are part of an auto-regulatory IRE1 RNase network. RIDD targets could possibly impact on the splicing of XBP1 mRNA, thus fine-tuning the response to ER stress and impacting on subsequent cell fate decisions. We identified PTP1B mRNA as a RIDD target affecting XBP1s activity by dephosphorylating RtcB, the tRNA ligase that performs XBP1s ligation. The tyrosine kinase $\mathrm{c}-\mathrm{Abl}$ is also part of this network as it phosphorylates RtcB, thus revealing a post-translational regulatory mechanism of the IRE1 RNase signaling outputs. The study furthermore supports the true existence and dynamic nature of a UPRosome whose composition can determine the outcome of IRE 1 signaling. 


\section{Results}

\section{PTP1B contributes to XBP1 mRNA splicing and is a RIDD target}

We first hypothesized that proteins involved in the IRE1-XBP1 pathway could also be coded by RIDD target mRNA, and as such, contribute to the integration of both activities. To identify XBP1s regulators in the context of ER stress and RIDD substrates, we conducted two independent screens. First, a siRNA library against ER protein-coding RNAs was used to transfect HEK293T cells expressing a XBP1sluciferase reporter [22] (Fig. S1A). The cells were then subjected to tunicamycininduced ER stress, and luciferase activity was monitored to identify XBP1s positive and XBP1s negative regulators (Fig. 1A). We identified 23 positive and 32 negative regulators (out of a siRNA library targeting $>300$ hits) including candidates involved in i) metabolic processes (e.g. CH25H, DHCR7), ii) post-translational modifications (e.g. POMT2, DMPK), iii) ER-Associated Degradation (e.g. SYVN1, UBC6) and iv) cell growth (e.g. RRAS, CD74) (Fig. 1B). Second, to identify mRNA that could be cleaved by IRE1, we performed an in vitro IRE1 mRNA cleavage assay as described previously [23] (Fig. S1B) yielding a total of 1141 potential RIDD targets. XBP1s regulators that could also be subjected to RIDD-mediated degradation were determined by intersecting the hit lists from both screens, yielding 7 candidates, namely: ANXA6, ITPR3, PTPN1 (positive XBP1 mRNA splicing regulators), RYR2, TMED10, KTN1 and ITPR2 (negative XBP1 mRNA splicing regulators). Interestingly, among the 7 hits found was PTPN1, that encodes for the Protein-Tyrosine Phosphatase 1B (PTP1B), a protein previously reported by us to potentiate XBP1 splicing in response to ER stress [25]. The lists from this study were later combined with a list of XBP1s regulators identified in a genome-wide siRNA screen [24]. Although we did not observe any common XBP1 mRNA splicing modulators with our own study, likely explained by a sensitivity issue due to the targeted aspect of the library used in the present work, we noted the existence of 33 more hits in the intersection between XBP1 splicing and RIDD. The functional association network of the reported candidates showed their involvement in UPR regulation, RNA processing and cellular homeostasis (Fig. 1C, D).

We next confirmed our previously obtained results [25] using RT-qPCR experiments that showed that PTP1B ${ }^{-/-}$(KO) mouse embryonic fibroblasts (MEFs) exhibited reduced XBP1 mRNA splicing compared to their PTP1B ${ }^{+/+}(w t)$ counterparts 
upon exposure to tunicamycin (Fig. 1E, Fig. S1C). The analysis of the other arms of the UPR downstream of the ATF6 and PERK sensors showed that the expression of both BiP and HERPUD mRNA was also attenuated in $\mathrm{PTP}^{-1 /} \mathrm{B}^{-/}$cells while that of CHOP mRNA was increased, most likely as a compensatory mechanism (Fig. S1EG). Using the same experimental system, we also observed a basal activity of all three UPR sensors (Fig. S1H). We next sought to test whether PTP1B mRNA was indeed a RIDD substrate. To this end, we used U87 cells expressing a dominant negative form of IRE1a (IRE1 DN) or an empty vector (EV) [26]. We conducted an Actinomycin $D$ chase experiment under basal or ER stress conditions to evaluate the post-transcriptional regulation of PTP1B mRNA expression. Under basal conditions, U87 DN cells showed higher expression levels of PTP1B compared to the control cells (Fig. 1F). Moreover, upon ER stress (DTT or Tunicamycin), PTP1B mRNA degradation was more efficient in control cells than in DN cells (Fig. 1G, Fig. S1I). Collectively, these results show that PTP1B mRNA is a genuine RIDD target and that PTP1B promotes IRE1-dependent XBP1 mRNA splicing.

\section{RtcB is tyrosine-phosphorylated by C-Abl and dephosphorylated by PTP1B}

Based on the experiments reported above, we concluded that PTP1B may represent a key regulator of IRE1 activity and investigated how this protein could mechanistically alter IRE1 signaling. PTP1B is a tyrosine phosphatase, and thus we first searched the PhosphoSitePlus database [27] for the presence of phosphotyrosine residues in proteins described previously to regulate IRE1/XBP1s signaling. This revealed that while there was no reported phosphotyrosine residue for IRE1 (a result confirmed experimentally in our laboratory), six phosphotyrosine residues were reported for $\mathrm{RtcB}$ and found in phosphoproteomics studies (Table S1, [27-29]). Interestingly, multiple protein sequence alignment of the human RtcB and its orthologues in different species from the metazoan/animal kingdom revealed not only a high conservation of the protein across evolution, but also the conservation of specific tyrosine residues (Fig. S2A). To monitor RtcB tyrosine phosphorylation in cellular models, we transfected HEK293T cells with the pCMV3-mouse RTCB-Flag (mRtcB) plasmid and left these untreated or treated them with the tyrosinephosphatase inhibitor bpV(phen). Cell extracts were immunoprecipitated with antiFlag antibodies, and the immune complexes were immunoblotted using antiphosphotyrosine ( $p Y$ ) antibodies. BpV(phen) treatment augmented the $\mathrm{pY}$ signal in 
the whole cell lysates (Fig. S2B) and showed that RtcB-Flag exhibited increased tyrosine phosphorylation (Fig. 2A, arrowhead). An identical result was observed with the endogenous RtcB (Fig. S2C).

We then tested whether RtcB interacts with PTP1B. To this end, HEK293T cells were transfected with RtcB-Flag and either wt PTP1B or PTP1B-C215S (trapping mutant $[30,31]$ ) plasmids. Cell extracts were immunoprecipitated using anti-PTP1B antibodies and the immune protein complexes were immunoblotted using anti-RtcB antibodies. RtcB-Flag exhibited a more stable association with the C215S PTP1B than what was observed for its wild-type form (Fig. 2B), suggesting that the pY residue(s) in RtcB might be trapped by the mutant PTP1B. To further document the functional relationship between PTP1B and the tyrosine phosphorylation of RtcB, the mRtcB-Flag plasmid was transfected in PTP1B ${ }^{-/}$and PTP1B ${ }^{+/+} \mathrm{MEFs}$, and the RtcBFlag phosphotyrosine status was evaluated as described above. This revealed that the pY signal of mRtcB-Flag was increased in $\mathrm{PTP}^{-\mathrm{B}^{-/}}$MEFs when compared to $\mathrm{PTP} \mathrm{B}^{+/+} \mathrm{MEFs}$ (Fig. 2C), which demonstrates that PTP1B is involved in the dephosphorylation of RtcB.

We next sought to identify a tyrosine kinase that could be responsible for RtcB phosphorylation. A recent study showed that the tyrosine kinase c-Abl acts as a scaffold for IRE1 by assisting its oligomerization and thus enhancing terminal UPR but is not involved in IRE1 phosphorylation [32]. In line with these results, we observed the significantly reduced mRtcB-Flag tyrosine phosphorylation when cells were treated with the tyrosine kinase inhibitor dasatinib which targets $\mathrm{C}-\mathrm{Abl}$ and which may also affect the activity of other tyrosine kinases such as Src family kinases (Fig. 2D, Fig. 2E). To further document the possible phosphorylation of RtcB by cAbl, we performed an in vitro kinase assay using recombinant human His-tagged c$\mathrm{Abl}$ as kinase and recombinant human GST-RtcB as substrate. This experiment showed that c-Abl phosphorylated RtcB in vitro (Fig. S2D). We then mapped the tyrosine phosphorylation sites on RtcB using mass spectrometry and identified three tyrosine residues Y306, Y316 and Y475 (Fig. 2F), which were also previously reported in independent proteomics screens (Table S1). Among them, the LVMEEAPESpY ${ }^{475} \mathrm{~K}$ phosphopeptide was found not only in the $\mathrm{TiO}_{2}$-purified but also in the crude sample indicating its probable greater abundance. 


\section{Molecular dynamics simulations of tyrosine phosphorylated RtcB and possible outcomes}

We next evaluated the impact of tyrosine phosphorylation on RtcB structure using molecular dynamics (MD) simulations. The starting structure was a recent homology model of the human RtcB protein [33]. The systems that were prepared and subjected to MD simulations were distinguished by the presence (active) or absence (inactive) of bound GMP at the active site of RtcB, and by the different combinations of phosphotyrosines. After the simulations, certain conformational differences on the RtcB systems such as the movement of helices or specific amino acids were observed (Fig. 3A, B, Fig. S3, 4). By itself, the addition of a phosphoryl group to a tyrosine gives a negative charge to this modified amino acid, that in turn induces local changes to both the electrostatic surface and the conformation. Collectively, these alterations can have implications on protein structure, substrate specificity and interaction surface. To quantify these changes, we performed post-MD analyses including determination of the $\underline{\text { Solvent }}$ Accessibility $\underline{\text { Surface }}$ Area (SASA) and pKa values for the three tyrosine residues, as well as characterization of each tyrosine residue as "buried" within the protein structure or more solvent exposed (Table S2, S3). In addition, we quantified the dihedral angles for each of the three tyrosines in all the different RtcB systems as a measure of their rotation (Fig. $3 \mathbf{C}$ ). We observed that when RtcB is fully phosphorylated, Y306 completely changes orientation to become more solvent exposed than buried in the body of the protein (Fig. 3D, Fig. 3A, B). pY306 is characterized as a residue existing in both fully buried and solvent-exposed conformations (Table S2). Consistently, analysis of the final structures after the 200ns simulations revealed that, although the differences in the SASA values are not striking, pY306 has the highest value of SASA among the three phosphotyrosines (pY306/pY316/pY475), and a higher SASA value than Y306 in the non-pY system (Table S3). Next, we measured the docking score of GTP in the active site of RtcB in the differentially tyrosine phosphorylated systems. Phosphorylation of $Y 475$ totally abrogated the binding of GTP in the active site (Fig. 3E, F). This is not surprising since Y475 is located at the active site of the protein and the bulky phosphoryl group creates a barrier that does not allow GTP to bind to the His 428 residue for the subsequent enzymatic catalysis. 


\section{Cellular impact of RtcB tyrosine phosphorylation}

We then investigated the cellular impact of RtcB tyrosine phosphorylation. To this end, we generated RtcB-Flag Y-to-F mutants (Fig. 4A) using site-directed mutagenesis to prevent phosphorylation by removing the hydroxyl of the side chain on the aromatic ring of the amino-acid. Single (Y306F, Y316F, Y475F), double (Y306F/Y316F) and triple (Y306F/Y316F/Y475F) mutants were obtained. HEK293T cells were transfected with the wt and mutant plasmids, treated with $\mathrm{bpV}(\mathrm{phen})$ and lysates were then immunoprecipitated using anti-Flag antibodies. Immunoblot with anti-pY antibodies revealed that while the Y306F and Y316F single mutants showed similar levels of tyrosine phosphorylation to $\mathrm{wt}$, the $\mathrm{Y} 475 \mathrm{~F}$ mutant had a reduced degree of tyrosine phosphorylation indicating a potential preference for this residue by c-Abl (Fig. 4B). The double Y306F/Y316F mutant showed reduced tyrosine phosphorylation compared to the corresponding single mutants (Fig. 4B). The triple mutant still displayed tyrosine phosphorylation suggesting that other Tyrosine residues could be phosphorylated most likely by other tyrosine kinases. Quantitation of the Western blots indicated a decrease in tyrosine phosphorylation correlating with the number of $Y$ to $F$ conversion (Fig. 4C). The additional phosphotyrosine residues found in previous mass spectrometry-based analyses are shown in Table S1. The interaction of each RtcB mutant with the substrate trapping mutant PTP1B-C215S was also tested as described earlier for the wt form of RtcB in Fig. 2B. Although there was no significant change in the interaction of each individual mutants with PTP1B-C215S, the double (Y306F/Y316F) and mostly the triple (Y306F/Y316F/Y475F) mutants showed a statistically significant reduction of their physical association with the PTP1B trapping mutant compared to the wt form of RtcB (Fig. S5A, B). This could indicate PTP1B lack of selectivity towards phosphoRtcB and suggests that PTP1B could dephosphorylate all three sites Y306, Y316 and Y475 in an interchangeable manner. Following this observation, we generated HeLa cell lines stably expressing either the wt or the above-described mutant forms of RtcB-Flag (including also the catalytically inactive mutant H428A) (Fig. 4A). Cycloheximide chase-experiments were conducted on these cells to compare the protein stability of each RtcB-Flag forms. These analyses revealed that all RtcB-Flag proteins displayed a similar half-life (Fig. 4D-E, S6A-B) which was comparable to that of the endogenous RtcB (Fig. 4D-E, S6C). In conclusion, even though the 
expression of some variants (e.g. Y475) appeared less efficient than the wt form of RtcB, determination of the half-lives did not show any noticeable variation.

\section{Phosphorylation of RtcB at Y306 attenuates XBP1 mRNA splicing and enhances RIDD activity}

Since we confirmed that RtcB could be phosphorylated in cells, we next tested the impact of these phosphorylation sites on XBP1 mRNA splicing. To this end, we treated HeLa cells stably expressing RtcB-Flag mutants with $1 \mu \mathrm{g} / \mathrm{ml}$ Tun for $0,2,4$, 8, 16 and 24 hours to monitor XBP1 mRNA splicing (Fig. 5A, D), and the results were normalized to the expression of RtcB-Flag (Fig. 5C, F), to report the RtcB-Flag specific activity with respect to XBP1 mRNA splicing (Fig. 5B, E). We observed that cells expressing the Y306F RtcB-Flag showed increased XBP1 mRNA splicing activity in response to ER stress (Fig. 5A, B). Furthermore, cells expressing the double mutant exhibited reduced XBP1 mRNA splicing compared to the wt RtcB-Flag but performed slightly better than cells expressing the catalytically inactive mutant H428A (Fig. 5D, E). The latter observation matched MD simulations results indicating that phosphorylation of RtcB on Y475 abrogates the binding of GTP in the active site of the protein, thereby halting its catalytic activity. Interestingly, cells expressing the triple mutant showed a slightly lower XBP1 mRNA splicing than those expressing the H428A mutant thereby suggesting that the complete absence of c-Ablphosphorylated tyrosines negatively affects RtcB in its contribution to XBP1 mRNA splicing (Fig. 5D, E). Because of the observed effect of Y306F RtcB on XBP1 mRNA splicing, we wondered whether RIDD activity would also be affected. To address this, we performed an Actinomycin D chase experiment under ER stress (induced by either Tun or DTT) and monitored the expression of PER1 and SCARA3 mRNAs, two known RIDD substrates. Upon ER stress Y306F RtcB-Flag-expressing cells showed higher levels of PER1 and SCARA3 mRNA compared to the wt cells (Fig. 5G) corresponding to a lower RIDD activity. The same observation was made even when endogenous RtcB was knocked-down using an siRNA targeting the 3'-UTR of the RTCB mRNA (Fig. 5G, H). Despite the changes in XBP1 mRNA splicing and RIDD activity, when the splicing of the three intron-containing tRNA molecules in human (corresponding to the Tyr, Arg and Ile tRNA) was compared between the Y306F and the wt RtcB-Flag-expressing cells, there was no change in tRNA splicing activity (Fig. 5I). As a control to this experiment the levels of the intron-less tRNA molecules Pro 
and Val were also tested (Fig. 5J). These results indicated that phosphorylation of RtcB on Y306 represents a major regulatory mechanism to control the balance between XBP1 mRNA splicing and RIDD activity downstream of IRE1 RNase. The specificity of this regulation becomes even more apparent by the fact that tRNA splicing is not influenced by the RtcB Y306F mutation.

\section{Non-phosphorylable RtcB Y306 (Y306F) rescues a defective XBP1 mRNA splicing and confers resistance to ER stress-induced cell death}

Based on the observations obtained in MD simulations that pY306 is almost totally exposed to the solvent and not buried within the protein in its fully-pY form, and in the XBP1 mRNA splicing time-course showing that Y306F RtcB-Flag has a much higher XBP1 splicing activity, we next tested if the phosphorylation of Y306 impacted on the interaction of RtcB with IRE1. This interaction was previously reported and shown to contribute to proper XBP1 mRNA splicing [6]. HEK293T cells were therefore cotransfected with IRE1 wt and either the wt or the mutant forms of RtcB-Flag plasmids. Twenty-four hours post-transfection, cell lysates were immunoprecipitated with antiFlag antibodies and immunoblotted with anti-IRE1 antibodies. We confirmed the interaction between IRE1 and RtcB (Fig. 6A) and found that the Y306F RtcB-Flag mutant exhibited a stabilized interaction with IRE1 compared to the wt form (Fig. 6A). The interaction of RtcB wt and its pY306 variant with IRE1 and XBP1 were then modeled (Fig. 6B). In the absence of XBP1 mRNA (red), the protein-protein docking showed that RtcB wt was able to bind essentially anywhere on the IRE1 tetramer surface with no specific preferred site of interaction. However, upon XBP1 binding, the RtcB wt docking revealed two symmetrically positioned sites of interaction, one at each dimer, close to the corresponding XBP1 splicing site (Fig. 6B, top panels). RtcB is oriented such that Y306 does not interact explicitly with IRE1/XBP1, whereas the catalytic area of RtcB is facing directly towards the cleavage site. Upon phosphorylation of $Y 306$, RtcB instead binds in a position between the two cleavage loops of XBP1, at the IRE1 dimer-dimer interface (Fig. 6B, lower panels). The phosphate group of pY306 is pointing towards/interacting with XBP1, and the catalytic region of RtcB is facing directly towards the IRE1 tetramer with no direct interaction towards the XBP1 mRNA. The free energies of binding as computed using MM-GBSA theory is similar for both wt and pY306 RtcB, albeit slightly stronger for the non-phosphorylated variant $\left(-50.2\right.$, and $-45.7 \mathrm{kcal} \mathrm{mol}^{-1}$, respectively), These 
docking calculations display a clear difference in the interaction of RtcB vs pY306 RtcB, with the wt system being perfectly oriented so as to interact with the spliced ends of XBP1 upon cleavage. Since our observations suggested that the RtcB Y306dependent interaction could control the XBP1 mRNA splicing activity of the IRE1/RtcB complex, we thus reconstituted in vitro the splicing reaction using in vitro transcribed XBP1 mRNA, recombinant IRE1 cytosolic domain whose optimal concentration was empirically determined (Fig. S6D) and RtcB immunoprecipitated from cells. This reconstitution assay showed that as anticipated from our previous results, IRE1/RtcB Y306F spliced XBP1 mRNA more efficiently than the wt RtcB (Fig. 6C-E). This additional result urged us to test whether the Y306F mutant would rescue the defective XBP1 splicing observed in PTP1B ${ }^{-/}$MEFs (Fig. 1F, Fig. S7A, B). $\mathrm{PTP}_{1 \mathrm{~B}^{-/}}$and $\mathrm{PTP}^{+\mathrm{B}^{++}}$MEFs were either left untransfected or transfected with wt RtcB-Flag or Y306F RtcB-Flag plasmids (Fig. S7D) and monitored for XBP1 mRNA splicing upon treatment with 50ng/ml Tun for 0, 2, 4, 8, 16 and 24 hours (Fig. 6F). Both wt and Y306F RtcB-Flag rescued XBP1 mRNA splicing in PTP1B ${ }^{-/}$MEFs. Importantly, the evaluation of the percentage of XBP1s revealed an improved rescue of the Y306F RtcB-Flag consistent with the effect on the XBP1s activity observed in stable HeLa cell lines (Fig. 6F, G). The rescuing effect of Y306F RtcB-Flag was profound even under acute ER stress induced by a treatment with $10 \mu \mathrm{g} / \mathrm{ml}$ Tun for 6 hours (Fig. S7C). The importance of Y306 phosphorylation is reinforced by the successful docking of c-Abl with RtcB after MD simulation (Fig. S7E). The interacting residues on c-Abl (D325, D444) and RtcB (K279, R283, K357) create a surface of contact where Y306 of RtcB is well accessible to the active site of the kinase (Fig. S7F).

Based on the known pro-survival roles of XBP1 mRNA splicing, we then tested whether phosphorylation of RtcB Y306 could have an effect on cell survival/death upon stress. When cells stably over-expressing the wt or the Y306F form of RtcB were treated for 24 hours with increasing concentrations of DTT to induce ER stress, the survival advantage of Y306F RtcB expressing cells became apparent (Fig. 7A). Indeed Y306F RtcB-Flag expressing cells presented less necrosis when endogenous RtcB was knocked-down by using an siRNA targeting the 3'-UTR of the RTCB mRNA. This meant that the observed effect was solely due to the exogenously expressed Y306F RtcB mutant (Fig. 7A). Under these specific ER stress conditions, in contrast to necrosis (as shown in the Q1 quadrants of the flow cytometry results), 
early/late cell apoptosis detection was not obvious (quantification not shown) thus indicating that the cell death mechanisms triggered in our experimental might not be dependent of the apoptotic cascade. Efficient silencing of endogenous RtcB was confirmed by both qPCR using primers spanning the 3'-UTR of the RtcB mRNA (Fig. S7G) and immunoblotting (Fig. S7H). These results indicate that RtcB Y306 is a key residue in the IRE1-XBP1/RIDD signaling. It is phosphorylated by $\mathrm{C}-\mathrm{Abl}$ and dephosphorylated by PTP1B, and it regulates the interaction between RtcB and IRE1. Further to this, we propose that phosphorylation of RtcB on Y306 is able to direct a decision towards cell death in the presence of ER stress downstream of the IRE1 RNase signaling outputs. To further document the role of the pY-dependent interaction between RtcB and IRE1 in the control of cell death, we relied on the recent discovery that DNA-damaging agents signaled through RIDD [34] and hypothesized that forcing the splicing of XBP1 mRNA through the expression of Y306F RtcB should sensitize the cells to cell death. To test this, cells expressing wt or Y306F RtcB were treated with Doxorubicin or Etoposide and in both cases Y306F RtcB expressing cells were more prone to apoptosis than cells expressing wt RtcB (Figure 7B), thereby indicating that the balance between XBP1 mRNA splicing and RIDD i) is tightly controlled by RtcB and ii) determines the nature of the biological output depending on the stress cells are exposed to. 


\section{Discussion}

The objective of this study was to better characterize how XBP1 mRNA splicing and RIDD activities can crosstalk and how their signals are integrated to control cellular response to ER stress. We showed that the tyrosine phosphorylation-dependent regulation of RtcB interaction with IRE1 might represent a mechanism to shift IRE1 activity from XBP1 mRNA splicing to RIDD. We have identified c-Abl as a tyrosine kinase responsible for the phosphorylation of RtcB on the three sites Y306, Y316 and Y475, and PTP1B as a tyrosine phosphatase de-phosphorylating RtcB. The phosphorylation of Y475 on RtcB, a residue located in the active site, attenuated XBP1 mRNA splicing. Indeed, the phosphorylation of Y475 prevents GTP binding to $\mathrm{H} 428$, thus halting the process of ligation. Surprisingly, phosphorylation of Y306 disrupted the interaction between RtcB and IRE1 thus reducing XBP1 mRNA splicing activity. We hypothesize that this mechanism could in turn favor an increase in RIDD activity upon stress. In the same line of evidence, the mutant Y306F RtcB rescued the defective XBP1 splicing observed in $\mathrm{PTP} 1 \mathrm{~B}^{-/}$cells indicating that phosphorylation on this specific residue impacts negatively on the XBP1s activity and constitutes a PTP1B-dependent mechanism in the UPR. Moreover, the fact that the mutant Y306F RtcB conferred resistance to ER stress-induced cell death poses the Y306 phosphorylation as a key cellular event allowing life/death decisions to be determined (Figure 7C).

Our data confirm the model posed as our initial hypothesis by demonstrating the existence of an auto-regulatory network emanating from the IRE1 RNase activity. In this regulatory network PTP1B was identified as a key actor by dephosphorylating RtcB, thereby facilitating the activation of the IRE1/XBP1s axis. In the meantime, PTP1B mRNA is a RIDD substrate such that when RIDD becomes dominant, PTP1B expression is prevented. Ultimately, one could propose a new model in which PTP1B would keep RtcB in a non-phosphorylated state thereby allowing the IRE1/RtcB complex to efficiently splice XBP1, hence exerting adaptive UPR. However, when the stress is un-resolvable, PTP1B expression would decrease through a RIDDdependent mechanism. In parallel c-Abl is recruited to the ER membrane [32] where it phosphorylates RtcB on Y306, Y316 and Y475, thus further inhibiting IRE1/RtcB interaction initially lowered by the reduction of PTP1B expression, and in the 
meantime, enhancing RIDD by prompting IRE1 oligomerization, hence resulting in terminal UPR.

It was demonstrated in a recent report that c-Abl can dissociate from 14-3-3 proteins in the cytosol upon ER stress, and be recruited to IRE1 foci at the ER membrane augmenting terminal UPR [32]. Herein, we show that c-Abl can act not only as a scaffold for IRE1 but also through its catalytic activity with the phosphorylation of RtcB on tyrosine residues that in turn causes the reduction of its XBP1 mRNA splicing activity. From our results and other studies, we can also speculate that apart from c-Abl, other tyrosine kinases might be involved in the regulation of the UPR. For instance, the Src tyrosine kinase has recently been reported to be activated by and bind to IRE1 under ER stress leading to ER chaperone-relocalization to the cell surface [35]. As such, the scaffolding role of IRE1 could represent a means to integrate multiple signaling pathways not yet known to be related to IRE1 signaling, and link them to a clear function in cell homeostasis.

In the present study, we identified RtcB as a new target of the tyrosine phosphatase PTP1B. Interestingly, besides our initial report that PTP1B is involved in the control of IRE1 activity [25], PTP1B was subsequently found to also target the PERK arm of the UPR by negatively regulating its activation through direct dephosphorylation [36]. As such, one might consider tyrosine kinase/tyrosine phosphatase signaling as a new key element in the regulation of the UPR to control life and death decisions. Our findings indicate that tyrosine phosphorylation is a key regulator of XBP1 mRNA splicing by IRE1 and RtcB. In the molecular complex of IRE1 and RtcB, an additional member could potentially be the archease protein reported as a stimulatory co-factor of RtcB not only for tRNA but also for XBP1s ligation [7,37]. Our results demonstrate that the dynamic alteration of the constituents of a multi-protein complex at the ER membrane can drive its collective activities, which further supports the notion of a UPRosome in the control of cellular life and death decisions $[19,20]$. 


\section{Materials and Methods}

Materials - Tunicamycin (Tun), dithiothreitol (DTT), Actinomycin D, cycloheximide $(\mathrm{CHX})$ and sodium orthovanadate $\left(\mathrm{Na}_{3} \mathrm{VO}_{4}\right)$ were obtained from Sigma-Aldrich. The phosphatase inhibitor $\mathrm{bpV}$ (phen) and the tysosine kinase inhibitors afatinib, crizotinib and sorafenib were from Santa Cruz Biotechnologies. The tyrosine kinase inhibitors dasatinib and imatinib (Imatinib Mesylate - STI571) were from Selleckchem. Protease and phosphatase inhibitor cocktail tablets were from Roche through Sigma-Aldrich. Pierce ECL Western Blotting Substrate was from Thermo-Fisher Scientific. The pCMV3-mRTCB-Flag plasmid encoding the wt form of mouse RtcB was purchased from Sino Biological. The various mutant forms of this plasmid were made with the QuikChange II XL Site-Directed Mutagenesis Kit from Agilent using the appropriate primers each time (Table S4). The pcDNA3.1/Zeo-PTP1B wt and pcDNA3.1/ZeoPTP1B C215S plasmids were used as previously described [38]. The $\mathrm{PCDH}-\mathrm{CMV}$ IRE1a-EF1-Puro-copGFP was cloned in the lab as previously described [23].

Cell culture and transfection - HEK293T, HeLa cells, U87 cells bearing a dominant negative form of IRE1a (IRE1 DN) or an empty vector (EV) [26] and mouse embryonic fibroblasts (MEFs) wt or KO for PTP1B (obtained in [25]) were cultured in Dulbecco's modified Eagle's medium (DMEM) supplemented with $10 \%$ FBS at $37^{\circ} \mathrm{C}$ in a 5\% CO2 incubator. For the generation of HeLa cell lines stably expressing each one of the RtcB-Flag proteins, cells were first transfected using Lipofectamine 2000 (Thermo-Fisher Scientific) with $1 \mu \mathrm{g}$ of the corresponding plasmid. After 24 hours, the medium of the cells was changed to medium containing $600 \mu \mathrm{g} / \mathrm{ml}$ Hygromycin B (Thermo-Fisher Scientific) to start the selection process. The Hygromycin Bcontaining medium was replaced every three days for a total period of 21 days, when polyclonal populations of HeLa cells stably expressing each of the RtcB-Flag proteins were obtained. The stable cell lines were maintained in DMEM with $10 \%$ FBS containing $120 \mu \mathrm{g} / \mathrm{ml}$ Hygromycin B. Transient transfections were achieved using either polyethylenimine (PEI) for the HEK293T cells or Lipofectamine 2000 for the HeLa cells and the MEFs together with the desired plasmid. For preparation of the PEI solution, branched polyethylenimine (average $M_{w} \sim 25,000$ ) powder was purchased from Sigma-Aldrich. 
siRNA-based screening assay - The library of approximately 300 small-interfering RNAs (siRNA) against genes encoding ER proteins was used in previous studies [39]. Each siRNA (25 nM) was transfected into HEK293T cells by transfection with the Lipofectamine RNAiMAX reagent (Thermo-Fisher Scientific). The cells were then transfected with an XBP1s-luciferase reporter in which the firefly luciferase gene is fused to the XBP1 gene [22]: under basal conditions where XBP1 mRNA remains unspliced, a stop codon at the gene fusion is in-frame thus not allowing the luciferase to be expressed. In contrast, under ER stress conditions the splicing of XBP1 mRNA shifts the ORF (open reading frame) resulting in the loss of the stop codon downstream of XBP1 and the subsequent expression of luciferase. ER stress was after applied to the cells and sequentially the substrate of the luciferase enzyme, luciferin. The cells were then tested for the emission of light that after appropriate quantification and a value threshold set-up led to the distinction of two major groups of genes: XBP1s positive and XBP1s negative regulators. High values of luminescence ( $>1 \mathrm{AU}$ ) signify that efficient XBP1 splicing took place so the luciferase expression was allowed, thus marking the silenced genes as negative XBP1s regulators. The opposite is true for values $<1 \mathrm{AU}$ that place the silenced genes in the category of positive regulators of XBP1 mRNA splicing.

in vitro IRE1 mRNA cleavage assay - As described previously [23], in this assay total RNA was extracted from U87 cells and incubated or not with recombinant IRE1a protein (purchased from Sinobiologicals Cat: 11905-H20B) under the conditions reported previously [23]. The resultant RNA sequences from the cleaved and uncleaved conditions underwent polyA mRNA isolation, the final different groups (non-polyA: cleaved or uncleaved, and polyA: cleaved or uncleaved) were reverse transcribed and the respective cDNA material was hybridized on the Affymetrix GeneChip Human Transcriptome Array (HTA) 2.0, which covers the whole exonic regions of the human genome. Results were analyzed as described in [23] and allowed for the in vitro identification of potential RIDD substrates.

Immunoblot and Immunoprecipitation - For preparation of whole cell extracts, cells were incubated in RIPA buffer (50 mM Tris- $\mathrm{HCl} \mathrm{pH} \mathrm{7.5,} 150 \mathrm{mM} \mathrm{NaCl}, 1 \% \mathrm{NP}-40$, 0,5\% sodium deoxycholate, $0.1 \%$ SDS, $2 \mathrm{mM}$ EDTA and $50 \mathrm{mM} \mathrm{NaF)} \mathrm{supplemented}$ 
with protease and phosphatase inhibitors, for $20 \mathrm{~min}$ on ice. Cells were scraped and centrifuged at $4^{\circ} \mathrm{C}$ for $7 \mathrm{~min}$ at $17,000 \times \mathrm{g}$ to collect the supernatant containing the protein. The samples were applied to SDS-PAGE and analyzed by immunoblotting. Dilutions of primary antibodies used for immunoblotting were as follows: mouse monoclonal anti-FLAG M2 (Sigma-Aldrich), 1:2000; rabbit polyclonal anti-RtcB (Proteintech), 1:1000; for recognition of the human PTP1B, mouse monoclonal antiPTP1B (3A7) (Santa Cruz Biotechnologies), 1:1000; for recognition of the mouse PTP1B, rabbit polyclonal anti-PTP1B (ab88481) (Abcam), 1:1000; rabbit polyclonal anti-IRE1a (B-12) (Santa Cruz Biotechnologies), 1:1000; mouse cocktail anti-pY-HRP (PY-7E1, PY20) (Invitrogen/Thermo-Fisher Scientific), 1:2000, goat polyclonal antiActin (I-19) (Santa Cruz Biotechnologies), 1:1000; mouse monoclonal anti-VCP (BD Transduction Laboratories), 1:1000; rabbit polyclonal anti-CNX/Calnexin (kindly provided by Dr. John Bergeron, McGill University, Montreal, QC, Canada), 1:1000. Polyclonal goat anti-mouse, goat anti-rabbit and rabbit anti-goat secondary antibodies conjugated to HRP (Dako-Agilent) were used at a dilution of 1:7000, $1: 7000$ and 1:3500, respectively. For the immunoprecipitation (IP), the cells were lysed in CHAPS buffer (30 mM Tris- $\mathrm{HCl}$ pH7.5, $150 \mathrm{mM} \mathrm{NaCl}$ and 1.5\% CHAPS) supplemented with a cocktail of protease and phosphatase inhibitors. The cell lysis buffer was further supplemented with $1 \mathrm{mM}$ of the phosphatase inhibitor $\mathrm{Na}_{3} \mathrm{VO}_{4}$ when the immunoprecipitates were going to be tested for pTyr. The lysates were then incubated for $16 \mathrm{~h}$ at $4^{\circ} \mathrm{C}$ with the indicated IP antibody (1 $\mu \mathrm{g} A b / 1000 \mu \mathrm{g}$ protein). After this, protein G or anti-FLAG-M2 conjugated dynabeads (Thermo-Fisher Scientific) were first washed with CHAPS lysis buffer and/or PBS, then mixed with the protein/Ab mixture, incubated at room temperature for $20 \mathrm{~min}$ or at $4^{\circ} \mathrm{C}$ for $40 \mathrm{~min}$ with gentle rotation and washed with CHAPS and/ or PBS. Finally, the beads were eluted with $1 \times$ Laemmli Sample Buffer (LSB), heated at $55-95^{\circ} \mathrm{C}$ for 5 min and loaded to SDS-PAGE. For the immunoblotting, the suitable primary and secondary antibodies were used.

$R T$-PCR and RT-qPCR - Total RNA was extracted from cells using Trizol (ThermoFisher Scientific) according to the manufacturer's instructions. CDNA was synthesized from the total RNA using the Maxima Reverse Transcriptase enzyme, random hexamer primers, dNTP mix and the Ribolock RNase inhibitor (ThermoFisher Scientific). PCR was performed on the template cDNA using Phusion High- 
Fidelity DNA Polymerase and dNTP mix (Thermo-Fisher Scientific). Quantitative PCR was alternatively performed for the cDNA using the SYBRß Premix Ex Taq ${ }^{\mathrm{TM}}$ (Tli RNase H Plus) (TAKARA-Clontech) using a QuantStudio5 system (Applied Biosystems). The primer sequences used for these experiments were synthesized by Eurogentec and are shown in Table S4.

Cell death assay - HeLa cells stably expressing RtcB-Flag proteins were left untransfected or transfected with 10nM of a duplex siRNA sequence (Table S4; IDT, Integrated DNA Technologies) targeting the 3'-UTR of the RTCB mRNA. Forty-eight hours later the cells were treated with $0,1,2.5,5,7.5$ and $10 \mathrm{mM}$ DTT or $0,0.5,1$ and $2 \mu \mathrm{M}$ Doxorubicin or 0, 5, 10 and $20 \mu \mathrm{M}$ Etoposide for 24 hours. The cells were then collected in tubes, along with the corresponding supernatants and PBS washes, and centrifuged at $1700 \mathrm{rpm}$ or $750 \mathrm{xg}$ for $5 \mathrm{~min}$. The cell pellets were transferred in a round-bottom 96-well plate where 1x Annexin $\mathrm{V}$ buffer and Annexin $\mathrm{V}$ were added. After a 15 min-incubation at room temperature and a PBS wash, $2 \%$ FCS in PBS and 7-AAD were added to the samples. The latter were incubated at room temperature for 5 more min and then analyzed by FACS (NovoCyte 3000).

In vitro kinase assays - To perform an in vitro kinase assay, we used 0.36-0.5 $\mu \mathrm{g}$ of human recombinant His-tagged $\mathrm{ABL}$ (His-ABL1 or c-Abl: $126 \mathrm{kDa}$ ) from Carna Biosciences as the tyrosine kinase and $1 \mu \mathrm{g}$ of human recombinant GST-tagged RtcB (GST-C22orf28: $81.6 \mathrm{kDa}$ ) (P01) from Abnova as the substrate. These were incubated in $1 x$ kinase buffer $(25 \mathrm{mM}$ Tris- $\mathrm{HCl} \mathrm{pH} 7.5,10 \mathrm{mM} \mathrm{MgCl}, 1 \mathrm{mM} \mathrm{MnCl}$, $0.5 \mathrm{mM}$ DTT, $10 \mu \mathrm{M}$ ATP, $0.1 \mathrm{mM} \mathrm{Na}_{3} \mathrm{VO}_{4}$ and $5 \mathrm{mM} \beta$-glycerophosphate) in a total volume of $30 \mu \mathrm{l}$ at $37^{\circ} \mathrm{C}$ for $30 \mathrm{~min}$ or at RT for 2 hours. Upon completion of the reaction, $5 \times$ LSB was added to the reaction samples which were heated to $100^{\circ} \mathrm{C}$ and applied in a $6 \%$ SDS-PAGE.

In vitro reconstitution of XBP1u splicing - To reconstitute XBP1u splicing in vitro, a vector encoding XBP1u downstream of T7 promoter was used as template for the splicing substrate (plasmids were a kind gift from Dr Fabio Martinon, Lausanne, Switzerland). The splicing substrate XBP1u mRNA was prepared using a RiboMAXTM Large Scale RNA Production Systems-T7 kit (Promega) at $37^{\circ} \mathrm{C}$ for 3 hours. In vitro transcripts were purified with RNeasy kit (Qiagen). Flag-RtcB WT and Flag-RtcB 
Y306F proteins were purified from HeLa cells stably expressing the two proteins, respectively. Cell pellets were lysed in a buffer containing $30 \mathrm{mM}$ Tris- $\mathrm{HCl}, \mathrm{pH} 7.5$, $150 \mathrm{mM} \mathrm{NaCl}$ and 1.5\% CHAPS supplemented with a cocktail of protease and phosphatase. Flag-tagged RtcB proteins were affinity-purified from the lysates with anti-Flag M2 affinity-gel (Sigma) followed by extensive washes. The human recombinant IRE1 cytoplasmic domain was purchased from Sino Biological. The reconstituted in vitro XBP1u splicing assay was carried out at $37^{\circ} \mathrm{C}$ for 2 hours in Kinase buffer (2 mM ATP, 2 mM GTP, 50 mMTris-HCl pH 7.4, 150 mM NaCl, 1 mM $\mathrm{MgCl} 2,1 \mathrm{mM} \mathrm{MnCl}$, $5 \mathrm{mM} \beta$-mercaptoethanol). One $\mu \mathrm{g}$ XBP1u RNA, $250 \mathrm{ng}$ IRE1 protein and IP-purified Flag-RtcB on beads, were used for a $50-\mu$ splicing reaction. The spliced products were column-purified with RNeasy kit (Qiagen) for RT-PCR analysis. The PCR products were resolved on a $3 \%$ agarose gel.

Modeling of wt and phosphorylated RtcB - The starting structure for the molecular dynamics (MD) simulations was a homology model of the human RtcB protein [33]. For the modified versions of the protein regarding its tyrosine phosphorylation states, we edited the initial structure through YASARA (Yet Another Scientific Artificial Reality Application, v15.3.8) [40]. For the MD simulations using Gromacs 5.1 [41], preparation and generation of additional missing parameters to the AMBER ff14SB force field [42] was performed for each structure using the AmberTools17 package [43]. Since RtcB contains a $\mathrm{Mn}^{2+}$ ion in its active site, we employed the python-based metal center parameter builder MCPB.py (version 3.0) [44] included in AmberTools17 for the parameterization of the metal site. In addition, separate pdb files were generated for the non-standard amino acid of phosphorylated tyrosine (named "TYP") and GMP bound to H428 (named "HIG"), using standard protocols. The resulting topology and coordinate files from Amber were transformed to the respective Gromacs files in order to perform the necessary system preparations for the MD simulations. Each system was solvated with TIP3P water [45] under periodic boundary conditions with the minimum distance between any atom in the solute and the edge of the periodic box being $10.0 \AA$. $\mathrm{Na}^{+} / \mathrm{Cl}^{-}$counterions were added as appropriate for the neutralization of the system. Energy minimization was conducted until the force was less than $1000 \mathrm{~kJ} \mathrm{~mol}^{-1} \mathrm{~nm}^{-1}$, followed by a 100ps NVT and a 100 ps NPT equilibration, and a final 200ns classical MD simulation for each system, using the Gromacs 5.1 package [41]. The temperature was kept at $300 \mathrm{~K}$ by the 
velocity rescaling thermostat [46] with a coupling constant of $0.1 \mathrm{ps}$. In the NPT equilibration and MD simulation the pressure was kept at 1.0 bar using the ParrinelloRahman barostat [47] with a coupling time of 2.0 ps. The leap-frog algorithm [48] was used with an integration time-step of 2 fs and the LINCS algorithm [49] was used to apply constraints on all bonds. UCSF Chimera [50] was used to visualize the processed systems. For quality control of our simulations we calculated the RMSF and RMSD of our systems. Post-MD analyses also included calculation of the surface solvent accessible area via Gromacs, pKa values and percentage of surface/buried area of the key tyrosine residues via the PROPKA 3.0 part of the PDB2PQR web server 2.0.0 [51]. To determine the relative positions of the tyrosines of interest and illustrate if and how much they are rotated, we set as a fixed point the $\mathrm{Mn}^{2+}$ ion in the active site of RtcB and calculated the dihedral angles consisting of this metal ion and the $\mathrm{CA}, \mathrm{CB}$ and $\mathrm{O}$ atoms of the tyrosine residue (i.e. rotation about the $\mathrm{C} \alpha-\mathrm{C} \beta$ bond) using UCSF Chimera. For the representation of the dihedral angles, polar charts were created using the matlablib 2.1.2 in python [52]. Furthermore, we calculated the docking score of the ligand GTP in the active site of the different RtcB systems (without GMP in the active site). For this purpose, among the programs of the Schrödinger Suites 2018-1 package, we used Protein Preparation Wizard [53] to prepare the protein structure, LigPrep to prepare the GTP ligand and Glide [54] for receptor grid generation and XP ligand docking. The grid in which the ligand was allowed to dock was determined by analyzing the interactions between GMP and its surrounding amino acids in MOE (Molecular Operating Environment, 2016.01; Chemical Computing Group) [55].

Modeling of protein complexes - To explore the interaction of RtcB with the IRE1XBP1 complex, we used a recent model of the human IRE1 tetramer (dimer of dimers) [56], and the homology model of human RtcB [33]. The RNAComposer modeling webserver (http://rnacomposer.ibch.poznan.pl) [57] was used to predict the 3D structure of XBP1 mRNA based on the nucleotide sequence and its secondary structure [58]. The predicted model was refined and optimized using 3dRNA v.2.0 (http://biophy.hust.edu.cn/3dRNA) [59]. The HADDOCK [60] webserver was employed to predict the IRE1-tetramer/XBP1 complex. The cleavage site in both stem loops of XBP1 mRNA ( $G$ and $C$ nucleotides) [57] and active residues in the RNase domain of the IRE1 tetramer (i.e. His910 and Tyr892) [61] were defined as 
interacting regions in HADDOCK. For the docking of RtcB and its pTyr306 phosphorylated variant to either the IRE1 tetramer or the IRE1 tetramer/XBP1 complex, the webserver HDOCK [62] was employed, using a blind-docking strategy. The Schrödinger package (Schrödinger Inc, release 2020-4) was employed to calculate the free energy of binding in IRE1-tetramer/XBP1 and IRE1-XBP1/RtcB complexes using the molecular mechanics generalized Born surface area (MMGBSA) technique [63]. For the c-Abl - RtcB interaction, we used the active form of Abl (PDB-ID: 2GQG). The ATP molecule was aligned inside protein using Chimera, based on the crystal structure of ATP bound to the structurally similar kinase Src (PDB-ID: 5XP7). The proteins were docked using PatchDock [64], with Y306 (RtcB) and ATP (c-Abl) chosen as interacting units. Following visual inspection of obtained complexes, the best aligned complex was prepared for MD simulations as outlined above. In order for the complex to not immediately dissociate, a set of seven position restrained equilibrations, with gradually reduced restraints in each, were applied. Finally, the system was subjected to a 200 ns MD simulation without position restraints.

Bioinformatics tools - For the creation of Venn diagrams, we used the online tool http://bioinformatics.psb.ugent.be/webtools/Venn/. For the creation of gene networks and functional annotations, we used the online String database 11.0 (https://string$\mathrm{db} . \mathrm{org} /$ ) [65]. Multiple sequence alignments were done using Clustal Omega 1.2.4 [66]. The PhosphoSitePlus database was used for the search of reported tyrosine phosphorylation sites on the proteins of interest [27].

Mass spectrometry analysis - A scaled-up in vitro kinase reaction containing $0.9 \mu \mathrm{g}$ of human recombinant His-c-Abl (His-ABL1 or c-Abl: $126 \mathrm{kDa}$ ) and $5 \mu \mathrm{g}$ of human recombinant GST-RtcB in the same conditions as described above was carried out for mass spectrometry analysis. The proteins were ran on a pre-cast $8 \%$ polyacrylamide gel (Eurogentec) and stained with 10\% CBB . In-gel digestion was then performed with trypsin (cleavage site $=\mathrm{K} / \mathrm{R}$ ) or lys $\mathrm{C}$ (cleavage site $=\mathrm{K}$ ) and $90 \%$ of the mixture was purified on $\mathrm{TiO}_{2}$. as previously described [67]. The $\mathrm{TiO}_{2}-$ enriched phosphopeptide fraction and the crude material were analyzed with an Ultimate 3000 nano-RSLC (Thermo Scientific, San Jose California) coupled in line with an Orbitrap ELITE (Thermo Scientific, San Jose Califronia). Briefly, peptides 
were separated on a C18 nano-column with a linear gradient of acetonitrile and analyzed with a TOP10 HCD (Higher-energy C-trap Dissociation) data-dependent method. Data were processed by database searching with Proteome Discoverer 2.4 software (Thermo Fisher Scientific) using E. coli SwissProt database spiked with the sequence of GST-RtcB. Precursor and fragment mass tolerance were set at $10 \mathrm{ppm}$ and 0.02 Da respectively. Trypsin or LysC with up to 2 missed cleavages were set as enzyme. Oxidation ( $\mathrm{M},+15.995 \mathrm{Da})$, phosphorylation (+79.966 Da (Y) were set as variable modification and Carbamidomethylation $(C,+57.021)$ as fixed modification. Peptides and proteins were filtered with False Discovery Rate $<1 \%$. Data are available via ProteomeXchange with the identifier PXD023433.

Statistical analyses - Student's t-test, one-way ANOVA and two-way ANOVA were applied for the statistical analyses depending on the experimental setting through the GraphPad Prism 7.0a software. 


\section{Acknowledgements}

We thank Dr Anna Reymer, Dr Antonio Carlesso, Dr Samuel Genheden and Johanna Hörberg for training on computational chemistry/biology (UGOT, Göteborg, Sweden), $\mathrm{Dr}$ Aeid Igbaria for critical reading of the manuscript. This work was funded by grants from Institut National du Cancer (INCa PLBIO), SIRIC-ILIAD/Cancéropôle Grand Ouest to EC, Fondation pour la Recherche Médicale (FRM, équipe labellisée 2018) to EC and RP; by EU H2020 MSCA ITN-675448 (TRAINERS) and MSCA RISE734749 (INSPIRED) grants to EC and LAE. The Swedish Research Council (VR) and the Swedish National Infrastructure for Computing (SNIC) are gratefully acknowledged for funding and allocations of computing time at the C3SE and PDC supercomputing centers, respectively (LAE). AP is a Marie Curie early stage researcher funded by EU H2020 MSCA ITN-675448 (TRAINERS). AM was funded by the Fondation ARC pour la recherche contre le cancer. SJM was funded by the Vinnova Seal-of-Excellence programme 2019-02205 (CaTheDRA).

\section{Conflict of interest}

EC and LAE are founders of Cell Stress Discoveries Ltd. The authors declare no conflicting interests. 


\section{References}

1. Almanza A, Carlesso A, Chintha C, Creedican S, Doultsinos D, Leuzzi B, Luís A, McCarthy N, Montibeller L, More S, et al. (2019) Endoplasmic reticulum stress signalling - from basic mechanisms to clinical applications. FEBS $\mathrm{J} \mathbf{2 8 6}$ : 241-278.

2. Karagöz GE, Acosta-Alvear D, Nguyen HT, Lee CP, Chu F, Walter P (2017) An unfolded protein-induced conformational switch activates mammalian IRE1. elife 6: e30700.

3. Urano F, Wang X-Z, Bertolotti A, Zhang Y, Chung P, Harding HP, Ron D (2000) Coupling of Stress in the Endoplasmic Reticulum to Activation of JNK Protein Kinases by Transmembrane Protein Kinase IRE1. Science 287: 664666.

4. Calfon M, Zeng H, Urano F, Till JH, Hubbard SR, Harding HP, Clark SG, Ron D (2002) IRE1 couples endoplasmic reticulum load to secretory capacity by processing the XBP-1 mRNA. Nature 415: 92-96.

5. Lee K, Tirasophon W, Shen X, Michalak M, Prywes R, Okada T, Yoshida H, Mori K, Kaufman RJ (2002) IRE1-mediated unconventional mRNA splicing and S2P-mediated ATF6 cleavage merge to regulate XBP1 in signaling the unfolded protein response. Genes Dev 16: 452-466.

6. Lu Y, Liang FX, Wang X (2014) A Synthetic Biology Approach Identifies the Mammalian UPR RNA Ligase RtcB. Mol Cell 55: 758-770.

7. Jurkin J, Henkel T, Nielsen AF, Minnich M, Popow J, Kaufmann T, Heindl K, Hoffmann T, Busslinger M, Martinez J (2014) The mammalian tRNA ligase complex mediates splicing of XBP1 mRNA and controls antibody secretion in plasma cells. EMBO J 33: 2922-2936.

8. Kosmaczewski SG, Edwards TJ, Han SM, Eckwahl MJ, Meyer BI, Peach S, Hesselberth JR, Wolin SL, Hammarlund M (2014) The RtcB RNA ligase is an essential component of the metazoan unfolded protein response. EMBO Rep 15: $1278-1285$.

9. Ray A, Zhang S, Rentas C, Caldwell KA, Caldwell GA (2014) RTCB-1 mediates neuroprotection via XBP-1 mRNA splicing in the unfolded protein response pathway. J Neurosci 34: 16076-16085.

10. Hollien J, Lin JH, Li H, Stevens N, Walter P, Weissman JS (2009) Regulated 
Ire1-dependent decay of messenger RNAs in mammalian cells. J Cell Biol 186: 323-331.

11. Hollien J, Weissman JS (2006) Decay of endoplasmic reticulum-localized mRNAs during the unfolded protein response. Science 313: 104-107.

12. Iwawaki T, Hosoda A, Okuda T, Kamigori Y, Nomura-Furuwatari C, Kimata Y, Tsuru A, Kohno K (2001) Translational control by the ER transmembrane kinase/ribonuclease IRE1 under ER stress. Nat Cell Biol 3: 158-165.

13. Lerner AG, Upton J-P, Praveen PVK, Ghosh R, Nakagawa Y, Igbaria A, Shen S, Nguyen V, Backes BJ, Heiman M, et al. (2012) IRE1a Induces ThioredoxinInteracting Protein to Activate the NLRP3 Inflammasome and Promote Programmed Cell Death under Irremediable ER Stress. Cell Metab 16: 250264.

14. Upton J-P, Wang L, Han D, Wang ES, Huskey NE, Lim L, Truitt M, McManus MT, Ruggero D, Goga A, et al. (2012) IRE1a cleaves select microRNAs during ER stress to derepress translation of proapoptotic Caspase-2. Science 338: 818-822.

15. Tam AB, Koong AC, Niwa M (2014) Ire1 has distinct catalytic mechanisms for XBP1/HAC1 splicing and RIDD. Cell Rep 9: 850-858.

16. Han D, Lerner AG, Walle L Vande, Upton J-P, Xu W, Hagen A, Backes BJ, Oakes SA, Papa FR (2009) IRE1a Kinase Activation Modes Control Alternate Endoribonuclease Outputs to Determine Divergent Cell Fates. Cell 138: 562575.

17. Korennykh A V, Egea PF, Korostelev AA, Finer-Moore J, Zhang C, Shokat KM, Stroud RM, Walter P (2009) The unfolded protein response signals through high-order assembly of Ire1. Nature 457: 687-693.

18. Maurel M, Chevet E, Tavernier J, Gerlo S (2014) Getting RIDD of RNA: IRE1 in cell fate regulation. Trends Biochem Sci 39: 245-254.

19. Hetz C, Glimcher LH (2009) Fine-Tuning of the Unfolded Protein Response: Assembling the IRE1a Interactome. Mol Cell 35: 551-561.

20. Hetz C, Papa FR (2018) The Unfolded Protein Response and Cell Fate Control. Mol Cell 69: 169-181.

21. Sepulveda D, Rojas-Rivera D, Rodríguez DA, Groenendyk J, Köhler A, Lebeaupin C, Ito S, Urra H, Carreras-Sureda A, Hazari Y, et al. (2018) Interactome Screening Identifies the ER Luminal Chaperone Hsp47 as a 
Regulator of the Unfolded Protein Response Transducer IRE1a. Mol Cell 69: 238-252.e7.

22. Spiotto MT, Banh A, Papandreou I, Cao H, Galvez MG, Gurtner GC, Denko NC, Le QT, Koong AC (2010) Imaging the unfolded protein response in primary tumors reveals microenvironments with metabolic variations that predict tumor growth. Cancer Res 70: 78-88.

23. Lhomond S, Avril T, Dejeans N, Voutetakis K, Doultsinos D, McMahon M, Pineau R, Obacz J, Papadodima O, Jouan F, et al. (2018) Dual IRE1 RNase functions dictate glioblastoma development. EMBO Mol Med e7929.

24. Yang Z, Zhang J, Jiang D, Khatri P, Solow-Cordero DE, Toesca DAS, Koumenis C, Denko NC, Giaccia AJ, Le Q-T, et al. (2018) A Human GenomeWide RNAi Screen Reveals Diverse Modulators that Mediate IRE1a-XBP1 Activation. Mol Cancer Res 16: 745-753.

25. Gu F, Nguyên DT, Stuible M, Dubé N, Tremblay ML, Chevet E (2004) Proteintyrosine phosphatase $1 \mathrm{~B}$ potentiates IRE1 signaling during endoplasmic reticulum stress. J Biol Chem 279: 49689-49693.

26. Drogat B, Auguste P, Nguyen DT, Bouchecareilh M, Pineau R, Nalbantoglu J, Kaufman RJ, Chevet E, Bikfalvi A, Moenner M (2007) IRE1 Signaling Is Essential for Ischemia-Induced Vascular Endothelial Growth Factor-A Expression and Contributes to Angiogenesis and Tumor Growth In vivo. Cancer Res 67: 6700-6707.

27. Hornbeck P V, Zhang B, Murray B, Kornhauser JM, Latham V, Skrzypek E (2015) PhosphoSitePlus, 2014: mutations, PTMs and recalibrations. Nucleic Acids Res 43: D512-20.

28. Tsai C-F, Wang Y-T, Yen H-Y, Tsou C-C, Ku W-C, Lin P-Y, Chen H-Y, Nesvizhskii Al, Ishihama Y, Chen Y-J (2015) Large-scale determination of absolute phosphorylation stoichiometries in human cells by motif-targeting quantitative proteomics. Nat Commun 6: 6622.

29. Bian Y, Li L, Dong M, Liu X, Kaneko T, Cheng K, Liu H, Voss C, Cao X, Wang $\mathrm{Y}$, et al. (2016) Ultra-deep tyrosine phosphoproteomics enabled by a phosphotyrosine superbinder. Nat Chem Biol 12: 959-966.

30. Jia Z, Barford D, Flint AJ, Tonks NK (1995) Structural Basis for Phosphotyrosine Peptide Recognition by Protein Tyrosine Phosphatase 1B. Science 268(5218):1754-8. 
31. Zhang Y-L, Yao Z-J, Sarmiento M, Wu L, Burke TR , Zhang Z-Y (2000) Thermodynamic Study of Ligand Binding to Protein-tyrosine Phosphatase 1B and Its Substrate-trapping Mutants. J Biol Chem 275(44):34205-12.

32. Morita S, Villalta SA, Feldman HC, Register AC, Rosenthal W, HoffmannPetersen IT, Mehdizadeh M, Ghosh R, Wang L, Colon-Negron K, et al. (2017) Targeting ABL-IRE1a Signaling Spares ER-Stressed Pancreatic $\beta$ Cells to Reverse Autoimmune Diabetes. Cell Metab 25: 1207.

33. Nandy A, Saenz-Méndez P, Gorman AM, Samali A, Eriksson LA (2017) Homology model of the human tRNA splicing ligase RtcB. Proteins Struct Funct Bioinforma 85: 1983-1993.

34. Dufey E, Bravo-San Pedro JM, Eggers C, González-Quiroz M, Urra H, Sagredo AI, Sepulveda D, Pihán P, Carreras-Sureda A, Hazari Y, Sagredo EA, Gutierrez D, Valls C, Papaioannou A, Acosta-Alvear D, Campos G, Domingos PM, Pedeux R, Chevet E, Alvarez A, Godoy P, Walter P, Glavic A, Kroemer G, Hetz C. Genotoxic stress triggers the activation of IRE1a-dependent RNA decay to modulate the DNA damage response. Nat Commun. 2020 May $14 ; 11(1): 2401$.

35. Tsai Y-L, Ha DP, Zhao H, Carlos AJ, Wei S, Pun TK, Wu K, Zandi E, Kelly K, Lee AS (2018) Endoplasmic reticulum stress activates SRC, relocating chaperones to the cell surface where GRP78/CD109 blocks TGF- $\beta$ signaling. Proc Natl Acad Sci 115: 201714866.

36. Krishnan N, Fu C, Pappin DJ, Tonks NK (2011) H2S-Induced Sulfhydration of the Phosphatase PTP1B and Its Role in the Endoplasmic Reticulum Stress Response. Sci Signal 4: ra86-ra86.

37. Popow J, Jurkin J, Schleiffer A, Martinez J (2014) Analysis of orthologous groups reveals archease and DDX1 as tRNA splicing factors. Nature 511: 104107.

38. Blanchetot C, Chagnon M, Dube N, Halle M, Tremblay M (2005) Substratetrapping techniques in the identification of cellular PTP targets. Methods 35: 44-53.

39. Higa A, Taouji S, Lhomond S, Jensen D, Fernandez-Zapico ME, Simpson JC, Pasquet JM, Schekman R, Chevet E (2014) Endoplasmic Reticulum StressActivated Transcription Factor ATF6a Requires the Disulfide Isomerase PDIA5 To Modulate Chemoresistance. Mol Cell Biol 34: 1839-1849. 
40. Krieger E, Vriend G (2014) YASARA View - molecular graphics for all devices from smartphones to workstations. Bioinformatics 30: 2981-2982.

41. Abraham MJ, Murtola T, Schulz R, Páll S, Smith JC, Hess B, Lindahl E (2015) GROMACS: High performance molecular simulations through multi-level parallelism from laptops to supercomputers. SoftwareX 1-2: 19-25.

42. Maier JA, Martinez C, Kasavajhala K, Wickstrom L, Hauser KE, Simmerling C (2015) ff14SB: Improving the Accuracy of Protein Side Chain and Backbone Parameters from ff99SB. J Chem Theory Comput 11: 3696-3713.

43. Case DA, Cerutti DS, Cheatham III TE, Darden TA, Duke RE, Giese TJ, Gohlke H, Goetz AW, Greene D, Homeyer N, Izadi S, Kovalenko A, Lee TS, LeGrand S, Li P, Lin C, Liu J, Luchko T, Mermelstein D, Merz KM, Monard G, Nguyen H, Omelyan I, Onufriev A, Pan F, Qi R, Roe DR, Roitberg A, Sagui C, Simmerling CL, Botello-Smith WM, Swails J, Walker RC, Wang J, Wolf RM, Wu X, Xiao L, York DM, Kollman PA (2017) AMBER 2017, San Francisco.

44. Li P, Merz KM (2016) MCPB.py: A Python Based Metal Center Parameter Builder. J Chem Inf Model 56: 599-604.

45. Jorgensen WL, Chandrasekhar J, Madura JD, Impey RW, Klein ML (1983). Comparison of simple potential functions for simulating liquid water. J. Chem. Phys. 79: 926-935.

46. Bussi G, Zykova-Timan T, Parrinello M (2009) Isothermal-isobaric molecular dynamics using stochastic velocity rescaling. J Chem Phys 130: 074101.

47. Parrinello M, Rahman A (1981) Polymorphic transitions in single crystals: A new molecular dynamics method. J Appl Phys 52: 7182-7190.

48. Van Gunsteren WF, Berendsen HJC (1988) A Leap-Frog Algorithm for Stochastic Dynamics. Mol Simul 1: 173-185.

49. Hess B, Bekker H, Berendsen HJC, Fraaije JGEM (1997) LINCS: A Linear Constraint Solver for Molecular Simulations. 18: 1463-1472.

50. Pettersen EF, Goddard TD, Huang CC, Couch GS, Greenblatt DM, Meng EC, Ferrin TE (2004) UCSF Chimera - A visualization system for exploratory research and analysis. J Comput Chem 25: 1605-1612.

51. Dolinsky TJ, Nielsen JE, McCammon JA, Baker NA (2004) PDB2PQR: an automated pipeline for the setup of Poisson-Boltzmann electrostatics calculations. Nucleic Acids Res 32: W665-7.

52. Droettboom M, Caswell TA, Hunter J, Firing E, Nielsen JH, Varoquaux N, Lee 
A, Andrade ES de, Root B, Stansby D, et al. (2018) matplotlib/matplotlib v2.1.2.

53. Madhavi Sastry G, Adzhigirey M, Day T, Annabhimoju R, Sherman W (2013) Protein and ligand preparation: parameters, protocols, and influence on virtual screening enrichments. J Comput Aided Mol Des 27: 221-234.

54. Friesner RA, Murphy RB, Repasky MP, Frye LL, Greenwood JR, Halgren TA, Sanschagrin PC, Mainz DT (2006) Extra Precision Glide: $\square$ Docking and Scoring Incorporating a Model of Hydrophobic Enclosure for Protein-Ligand Complexes. J Med Chem 49: 6177-6196.

55. Molecular Operating Environment (MOE) 2016.01; Chemical Computing Group Inc., Montreal, Canada, 2016.

56. Carlesso A, Hörberg J, Reymer A, Eriksson LA (2020) New insights on human IRE1 tetramer structures based on molecular modeling, Sci Rep 10:17490.

57. Popenda M, Szachniuk M, Antczak M, Purzycka KJ, Lukasiak P, Bartol N, Blazewicz J, Adamiak RW (2012) Automated 3D structure composition for large RNAs, Nucl Acids Res, 40:e112-e112.

58. Peschek J, Acosta-Alvear D, Mendez AS, Walter P (2015) A conformational RNA zipper promotes intron ejection during non-conventional XBP 1 mRNA splicing, EMBO reports, 16:1688-1698.

59. Wang J, Wang J, Huang Y, Xiao Y (2019) 3dRNA v2. 0: An Updated Web Server for RNA 3D Structure Prediction, Int J Mol Sci 20:4116.

60. Van Zundert G, Rodrigues J, Trellet M, Schmitz C, Kastritis P, Karaca E, Melquiond A, van Dijk M, De Vries S, Bonvin A (2016) The HADDOCK2. 2 web server: user-friendly integrative modeling of biomolecular complexes, $\mathrm{J}$ Mol Biol 428:720-725.

61. Sanches M, Duffy NM, Talukdar M, Thevakumaran N, Chiovitti D, Canny MD, Lee K, Kurinov I, Uehling D, Al-Awar R (2014) Structure and mechanism of action of the hydroxy-aryl-aldehyde class of IRE1 endoribonuclease inhibitors, Nat Comm 5:1-16.

62. Yan Y, Zhang D, Zhou P, Li B, Huang S-Y (2017) HDOCK: a web server for protein-protein and protein-DNA/RNA docking based on a hybrid strategy, Nucl Acids Res 45:W365-W373.

63. Rastelli G, Rio AD, Degliesposti G, Sgobba M (2010) Fast and accurate predictions of binding free energies using MM-PBSA and MM-GBSA, J Comp Chem 31:797-810. 
64. Schneidman-Duhovny D, Inbar Y, Nussinov R, Wolfson HJ (2005) PatchDock and SymmDock: servers for rigid and symmetric docking. Nucl Acids Res 33: W363-367.

65. Jensen LJ, Kuhn M, Stark M, Chaffron S, Creevey C, Muller J, Doerks T, Julien P, Roth A, Simonovic M, et al. (2009) STRING 8--a global view on proteins and their functional interactions in 630 organisms. Nucleic Acids Res 37: D412-6.

66. Sievers F, Wilm A, Dineen D, Gibson TJ, Karplus K, Li W, Lopez R, McWilliam H, Remmert M, Söding J, et al. (2011) Fast, scalable generation of high-quality protein multiple sequence alignments using Clustal Omega. Mol Syst Biol 7: 539.

67. Negroni L, Taouji S, Arma D, Pallares-Lupon N, Leong K, Beausang LA, Latterich M, Bossé R, Balabaud C, Schmitter JM, et al. (2014) Integrative quantitative proteomics unveils proteostasis imbalance in human hepatocellular carcinoma developed on nonfibrotic livers. Mol Cell Proteomics 13:3473-8 


\section{Figure Legends}

Figure 1. siRNA screening and in vitro IRE1 $\alpha$ cleavage assay identify PTP1B as both XBP1 splicing regulator and RIDD target. (A) siRNA-based screening assay: HEK293T cells were transfected with siRNA sequences against genes encoding ER proteins. They were subsequently transfected with an XBP1s-luciferase reporter (Fig. $\mathrm{S} 1 \mathrm{~A})$ and after $48 \mathrm{~h}$ and the induction of ER stress, the cells were tested for the intensity of light signal after the addition of luciferin. (B) Luminescence quantification of the screening assay described in (A). (C) Venn diagram of the gene list resulting from the assay described in (A-B), a list of possible RIDD substrates coming from an in vitro IRE1a cleavage assay (Fig. S1B) and a genome-wide siRNA-based screening assay (described in [24]). (D) A schematic network of the genes in the intersections of the lists as described in (C). (E) PTP1B ${ }^{+/+}(w t)$ and PTP1B ${ }^{-/-}(\mathrm{KO})$ mouse embryonic fibroblasts (MEFs) were treated for 0 and 6 hours with $10 \mu \mathrm{g} / \mathrm{ml}$ Tun. RNA was isolated and the resulting samples were analyzed with qPCR for spliced and total XBP1 mRNA levels. The bar graph presents the XBP1 mRNA splicing as the ratio of spliced XBP1 to total. For the latter, qPCR primers amplifying the region before the cleavage site or the region spanning the cleavage site were used (Fig. S1C). (F-G) PTP1B mRNA expression levels in U87 cells expressing or not a dominant negative form of IRE1a at Oh time-point $(F)$ and during DTT treatment $(1 \mathrm{mM})$ with a 2-hour Actinomycin D $(5 \mu \mathrm{g} / \mathrm{ml})$ pre-treatment $(\mathrm{G})$. EV: empty vector, IRE1 DN: dominant negative (cytosolic-deficient) form of IRE1a. Data values are the mean \pm SEM of $n \geq 3$ independent experiments $\left({ }^{*} p<0.05,{ }^{* *} p<0.01\right)$. Error bars for $(\mathrm{H})$ are not depicted.

Figure 2. RtcB is a substrate of the tyrosine kinase c-Abl and the tyrosine phosphatase PTP1B. (A) HEK293T cells were left untransfected (CTL) or transfected with $2 \mu \mathrm{g}$ of the pCMV3-mRTCB-Flag plasmid (RtcB-F) and treated 24 hours post-transfection with $15 \mu \mathrm{M}$ bpV(phen) for 2 hours. Immunoprecipitation was done in the cell lysates using Flag antibody and the immunoprecipitates were immunoblotted for phosphotyrosine. The membrane was re-probed with Flag and RtcB, sequentially. The corresponding input samples are also shown immunoblotted using anti-Flag, anti-RtcB, anti-pY-HRP antibodies and anti-Valosin Containing 
Protein (VCP) antibodies, VCP being used here as loading control. (B) HEK cells were left untransfected (CTL) or transfected with $1 \mu \mathrm{g}$ of the wt mouse RtcB-Flag plasmid and $1 \mu \mathrm{g}$ of either the wt PTP1B plasmid or the C215S mutant one. PTP1B immunoprecipitation was performed on the whole cell lysate using anti-PTP1B antibodies and the immunoprecipitates were immunoblotted with anti-RtcB and antiPTP1B antibodies. Lysate inputs were analyzed by immunoblotting for RtcB, Flag, PTP1B and VCP using the corresponding antibodies. (C) $\mathrm{PTP}^{1 \mathrm{~B}^{+/+}}$or PTP1B ${ }^{-/-} \mathrm{MEFs}$ were left untransfected $(\mathrm{C})$ or transfected with $2 \mu \mathrm{g}$ wt RtcB-Flag plasmid and treated with $15 \mu \mathrm{M}$ bpV(phen) for 2 hours. Immunoprecipitation was performed on whole cell lysates using anti-Flag antibodies and the immunoprecipitates were immunoblotted using HRP-conjugated anti-phosphotyrosine antibodies and the membrane was then re-probed with anti-Flag antibodies. Lysate inputs were analyzed by immunoblotting for Flag, RtcB, PTP1B, phosphotyrosine and VCP using the corresponding antibodies. (D) HEK293T cells transfected with the wt RtcB-Flag plasmid were treated 24 hours post-transfection with $10 \mu \mathrm{M}$ of tyrosine kinase inhibitors afatinib, crizotininb, dasatinib, imatinib and sorafenib for 8 hours and $15 \mu \mathrm{M}$ bpV(phen) for 2 hours. Immunoprecipitation was performed on whole cell lysates using anti-Flag antibodies and the immunoprecipitates were first immunoblotted using anti- pY-HRP antibodies and then re-probed using anti Flag antibodies. Input samples were analyzed by immunoblotting for phosphotyrosine, Flag and VCP using the corresponding antibodies. (E) The levels of pY-RtcB (D) was normalized to RtcB protein levels (D). The blots shown in (A-D) are representative of three or more independent experiments. In (A, C, D) the arrowhead denotes the RtcB-Flag protein. Data presented shown in the graph correspond to the mean \pm SEM of $n=3$ independent experiments $\left({ }^{* * *} p<0.0001\right)$. (F) MS/MS spectra of peptides with phosphorylated tyrosine (Y306, Y316, Y475) after in vitro phosphorylation of RtcB. Identified fragment ions $\mathrm{b}$ and $\mathrm{y}$ ions are indicated in red and blue, respectively.

\section{Figure 3. Molecular dynamics of RtcB tyrosine-phosphorylated systems and} possible implications. (A) Ribbon-like structures of the RtcB protein resulting from the MD simulations either non-phosphorylated (left) or phosphorylated at Y306, Y316 and Y475 (right). (B) Zoom-in at Y306, Y316 and Y475 after superposition of the two RtcB models shown in (A). (C) Scheme explaining the calculation of a dihedral angle for a tyrosine relative to the $\mathrm{Mn}^{2+}$ in the active site of RtcB. The example shows $\mathrm{Y} 306$ 
in the unphosphorylated RtcB system, and the angle of interest is the rotation about the $\mathrm{C} \alpha-\mathrm{C} \beta$ bond of the tyrosine residue. (D) The Mn-CA-CB-O dihedral angles in degrees $\left(^{\circ}\right)$ of each of the three tyrosines 306, 316 and 475 relative to the $\mathrm{Mn}$ ion in the protein active site in all RtcB systems after 200 ns MD simulation, depicted in polar charts. (E) Scheme showing the docked GTP ligand in the active site of the unphosphorylated RtcB protein. (F) Glide XP docking scores of GTP in the active site of the different RtcB systems.

\section{Figure 4. Generation of cellular models with altered RtcB tyrosine} phosphorylation status. (A) Scheme showing the RtcB-Flag protein encoded by the pCMV3-mouse RtcB-Flag plasmid and the mutant forms that were created in this study. (B) HEK293T cells were left untransfected (CTL) or transfected with $2 \mu \mathrm{g}$ of the different RtcB-Flag plasmids. Twenty-four hours post-transfection the cells were treated with $15 \mu \mathrm{M}$ bpV(phen) for 2 hours. Immunoprecipitation (IP) was performed on the cell lysates using anti-Flag antibodies and the immunoprecipitates were immunoblotted for phosphotyrosine using HRP-conjugated anti-pY antibodies. The membrane was re-probed with Flag. The corresponding input samples are also shown immunoblotted with anti-Flag and anti-VCP (VCP being used as loading control) antibodies. The arrowhead denotes the RtcB-Flag protein. The blot shown is representative of three independent experiments. (C) The levels of phosphorylated RtcB (B) was normalized to RtcB protein levels (B). (D) HeLa stable lines expressing wt or mutant RtcB-Flag were treated with $10 \mu \mathrm{g} / \mathrm{ml} \mathrm{CHX}$ for $0,1,2,4$ and 8 hours to block translation. RtcB-Flag expression levels were monitored using immunoblotting with anti-Flag antibodies in the resulting protein lysates. The Parental HeLa cells were included to additionally monitor the levels of the endogenous RtcB. VCP was used as a loading control. The blots shown here are representative of three independent experiments. (E) Half-life $\left(t_{1 / 2}\right)$ calculated for the different forms of the RtcB-Flag protein or the endogenous RtcB in the case of the Parental HeLa cells. Data presented shown in the graph correspond to the mean \pm SEM of $n=3$ independent experiments $\left({ }^{*} p<0.02\right)$.

Figure 5. Phosphorylation of RtcB on Y306 negatively affects XBP1 mRNA splicing but not RIDD activity. (A, D) HeLa lines stably expressing wt or mutant RtcB-Flag were treated with $1 \mu \mathrm{g} / \mathrm{ml}$ Tun for $0,2,4,8,16$ and 24 hours. 
Complementary DNA generated using RNA isolated from these were analyzed by qPCR for XBP1s and XBP1 total mRNA. The XBP1s/XBP1tot reflects XBP1 mRNA splicing and is depicted in the $y$ axis of the graphs. Parental HeLa cells are also included for comparison. (B, E) The peak of XBP1 mRNA splicing activity detected at 8 hours of treatment $(A, D)$ was then normalized to the protein levels $(C, F)$ to determine RtcB specific activity. (C, F) Stable HeLa lines were lysed and the lysates analyzed for RtcB-Flag expression using immunoblotting with anti-Flag antibodies. Actin was used as a loading control. (G) HeLa lines stably expressing wt or Y306F RtcB-Flag were left untransfected or transfected with an siRNA targeting the 3'-UTR of the RTCB mRNA. 48 hours post-transfection the cells were pre-treated for 2 hours with $5 \mu \mathrm{g} / \mathrm{ml}$ Actinomycin $D$ and then treated either with $5 \mu \mathrm{g} / \mathrm{ml}$ Tun for 4 hours or $1 \mathrm{mM}$ DTT for 2 hours. The graph shows the mRNA levels of PER1 (upper part) and SCARA3 (lower part) after normalization to the untreated samples (Oh time-point).

(H) RT-qPCR analysis of the untreated samples from $(\mathrm{G})$ for the endogenous RtcB mRNA using primers spanning its 3'-UTR. (I) cDNA from HeLa stable lines expressing wt or Y306F mutant RtcB-Flag was analyzed with qPCR for the splicing of the three intron-containing tRNA molecules in human Tyr, Arg and lle. The graph shows the percentage of each spliced tRNA molecule to their total levels (unspliced + spliced). The presented values have been normalized to the levels of \% tRNA splicing in Parental HeLa cells. (J) The levels of the intronless tRNA molecules Pro and Val were measured by RT-qPCR in the samples of (I). Values have been normalized to the levels measured in Parental HeLa cells. Data values for all the presented graphs are the mean \pm SEM of $n \geq 3$ independent experiments $\left({ }^{*} p<0.05\right.$, $\left.{ }^{* *} p<0.01\right)$. Error bars for $(A, D)$ are not depicted.

Figure 6. The Y306F RtcB mutant rescues a defective XBP1 mRNA splicing. (A) HEK cells were co-transfected with $1 \mu \mathrm{g}$ of wt IRE1 $\alpha$ and $1 \mu \mathrm{g}$ of wt or mutant RtcBFlag plasmid. 24 hours later, cell lysis and IP for Flag was performed. The immunoprecipitates were blotted for IRE1a and the input samples for IRE1a, Flag and Actin. The arrowhead denotes the RtcB-Flag protein. (B) Docked complexes of RtcB wt and pY306 variants towards the IRE1 tetramer/XBP1 complex. (Top panels) RtcB wt (green) binds at the loop-binding RNase area of IRE1 (blue) and is perfectly oriented to initiate the ligation of XBP1 (red) upon its cleavage by IRE1. (Lower panels) The interaction area of the phosphorylated RtcB is shifted towards the middle 
of XBP1 at the IRE1 dimer-dimer interface region, and will not be able to initiate the ligation reactions of the spliced ends at the two XBP1 loops (P-Y306 of RtcB is represented in yellow). (C) In vitro reconstitution of XBP1 mRNA splicing using in vitro transcribed XBP1 mRNA which was incubated with or without $250 \mathrm{ng}$ of recombinant IRE1 cytosolic domain and with WT or Y306F RtcB-Flag immunoprecipitated from cells. The retrotranscribed XBP1 DNA from the assay was analyzed by PCR using primers recognizing the XBP1 mRNA. (D) Immunoprecipitated RtcB levels were detected by IP in the cell lysates using antiFlag antibodies-coated beads and the immunoprecipitates were immunoblotted with anti-Flag antibodies. (E) XBP1s (C) was then normalized to RtcB protein levels (D) to obtain the RtcB specific activity. (F) PTP1B ${ }^{+/+}$(wt) and PTP1B ${ }^{-/-}$(KO) MEFs untransfected (CTL) or transfected with $2 \mu \mathrm{g}$ of wt or Y306F RtcB-Flag plasmid were treated 24 hours post-transfection with 50ng/ml Tun for 0, 2, 4, 8, 16 and 24 hours. Their cDNA was analyzed by PCR using primers recognizing the XBP1 mRNA. (G) Quantification of the gels in (F). (Right bar graph) The slope of each curve was calculated and for each condition the slope of the wt cells was subtracted from the one of the KO cells, called as $\triangle$ slope. Data values are the mean \pm SEM of $n \geq 3$ independent experiments (ns: non-significant, ${ }^{*} p<0.05,{ }^{* * *} p<0.001,{ }^{* * *} p<$ 0.0001 ). (only the + SEM values are shown for clarity purposes).

Figure 7. RtcB Y306 phosphorylation is a key event in modulating stressinduced cell life and death decisions. (A) HeLa lines stably expressing wt or Y306F RtcB-Flag were transfected or not with siRNA sequences against the endogenous RTCB mRNA. Forty-eight hours post-transfection the cells were treated with $0,1,2.5,5,7.5$ and $10 \mathrm{mM}$ DTT for 24 hours. The resulting samples were then analyzed by FACS for cell necrosis and apoptosis as indicated by 7-AAD and Annexin $V$ staining, respectively. Data values are the mean \pm SEM of $n \geq 3$ independent experiments (ns: non-significant, ${ }^{* * *} p<0.001,{ }^{* * * *} p<0.0001$ ). (B) HeLa cells stably expressing wt or Y306F RtcB-Flag were left untransfected or transfected with siRNA sequences against the endogenous RTCB mRNA. Forty-eight hours post-transfection the cells were treated with $0,0.5,1$ and $2 \mu \mathrm{M}$ Doxorubicin, or 0, 5, 10 and $20 \mu \mathrm{M}$ Etoposide for 24 hours. The resulting samples were then analyzed by FACS for cell necrosis and apoptosis as indicated by 7-AAD and Annexin V staining, respectively. Data from the treatments with $2 \mu \mathrm{M}$ Doxorubicin and $5 \mu \mathrm{M}$ Etoposide 
are shown. Data values are the mean \pm SEM of $n=4$ independent experiments in Two-Way ANOVA and post-Tukey multiple comparisons test $\left({ }^{*} p<0.05\right.$, ${ }^{* * *} p<$ 0.001). (C) Model representation of IRE1 activation and signaling towards XBP1s or RIDD. A decrease in PTP1B expression driven by RIDD is thought to reduce the formation of the IRE1/RtcB complex thereby pushing towards unleashed RIDD and terminal UPR. Dashed-lines indicate non demonstrated hypotheses. 

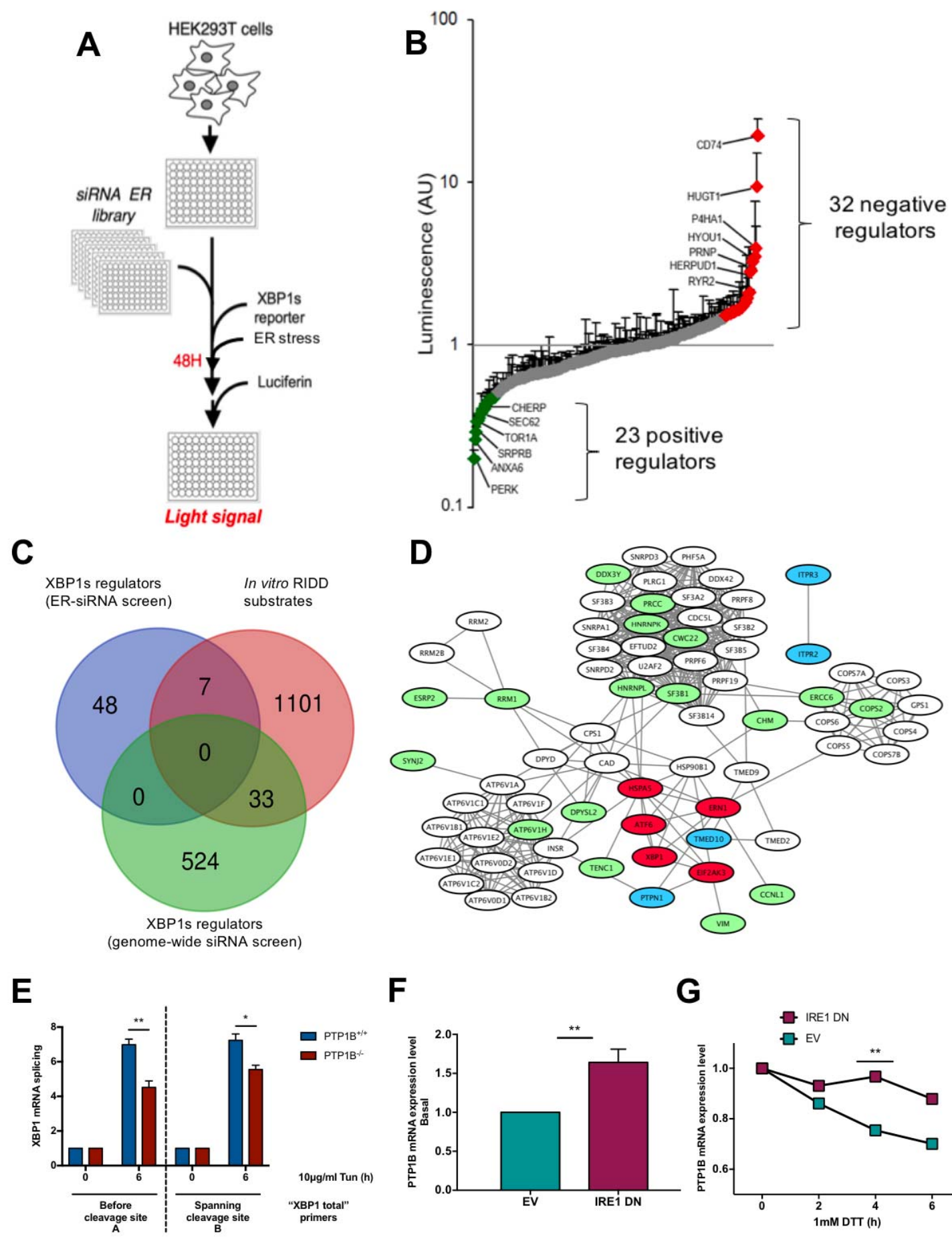

F
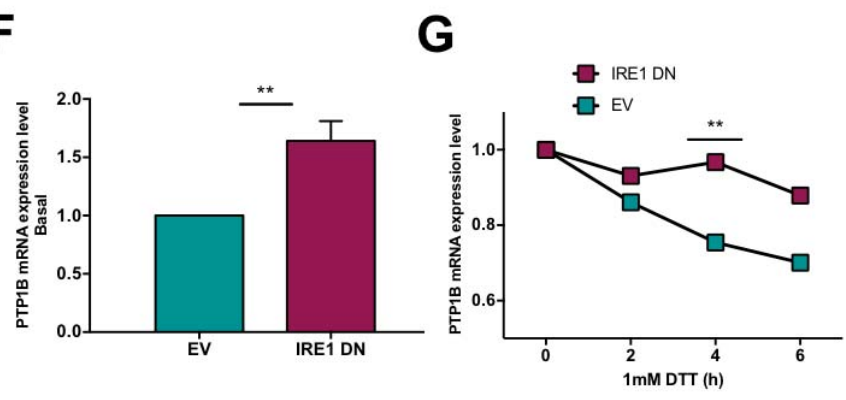

\section{FIGURE 1}


A

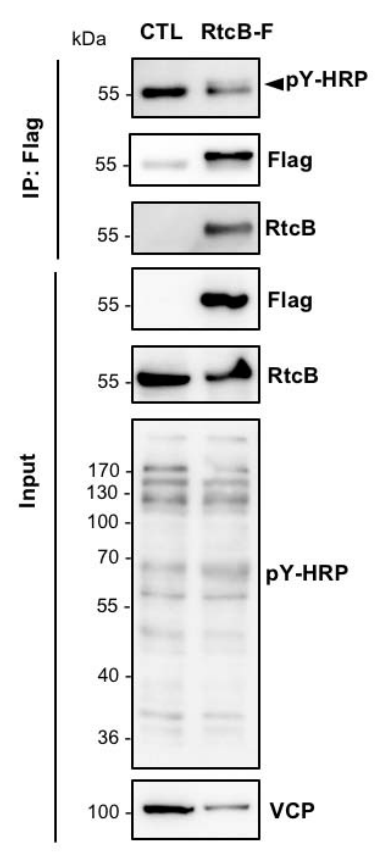

B
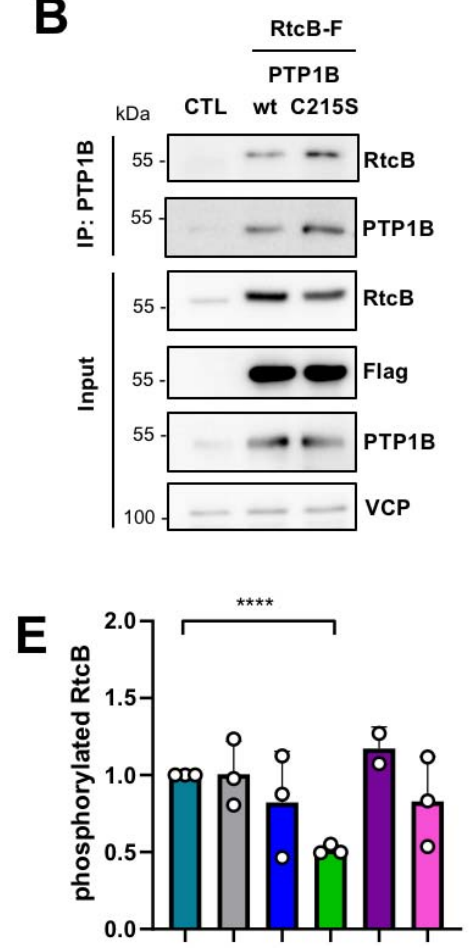

C
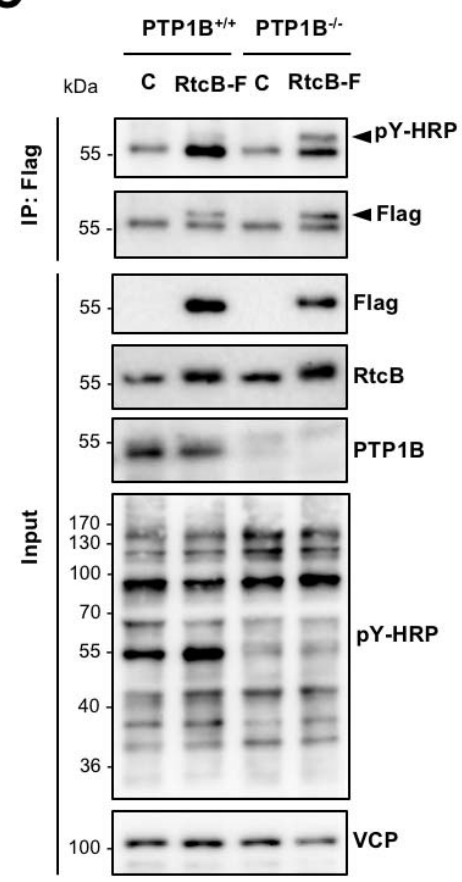

D

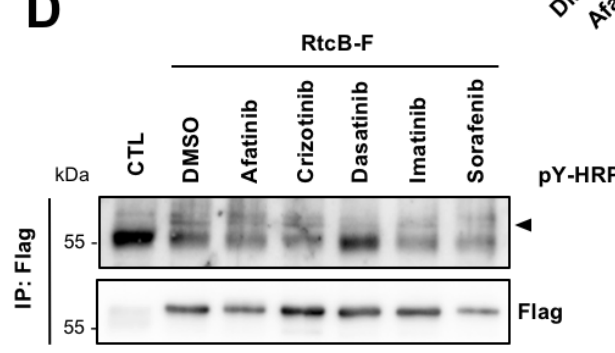

$F$
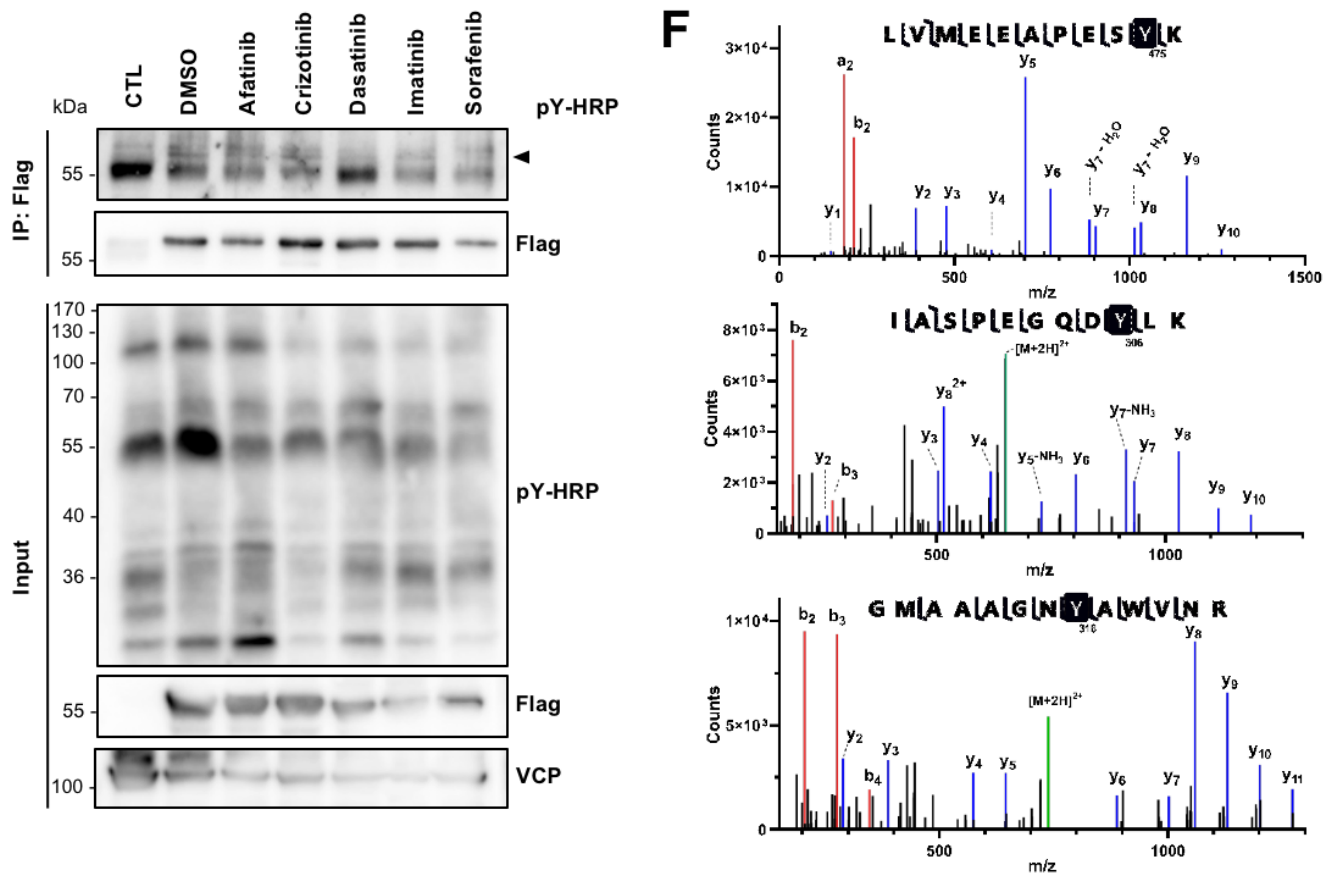

\section{FIGURE 2}


A

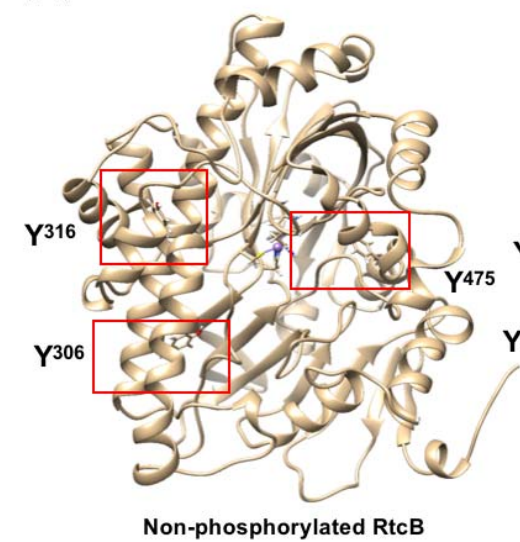

C

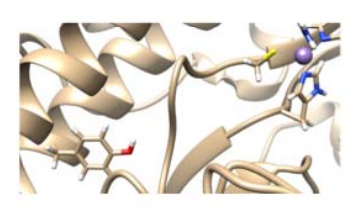

E

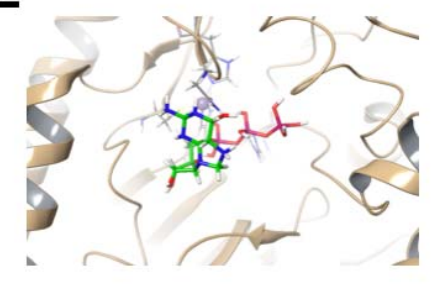

B
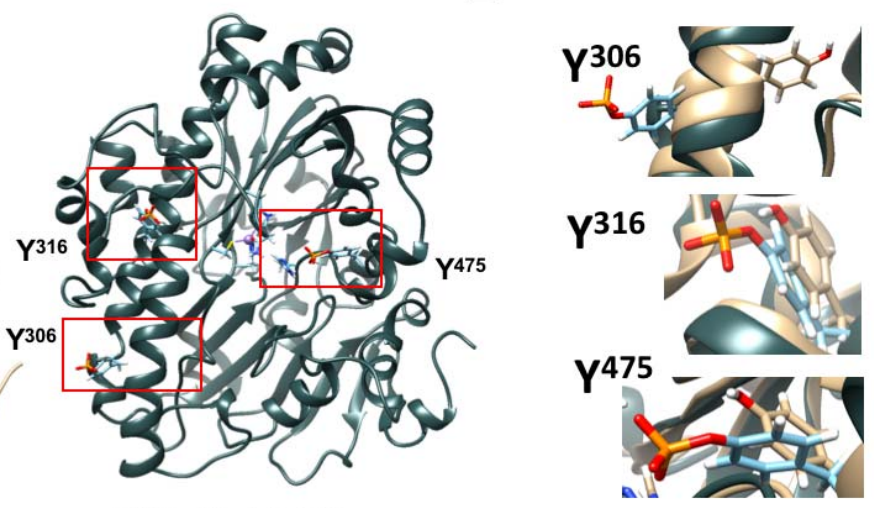

pY(306, 316, 475)-RtcB
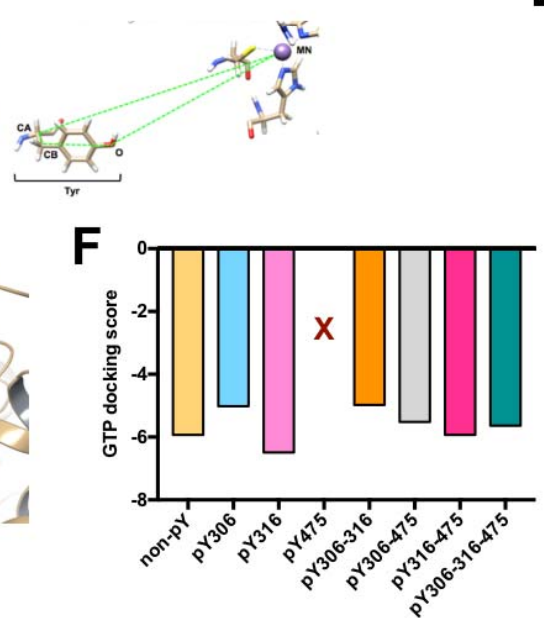

RtcB tyrosine phosphorylation status
D
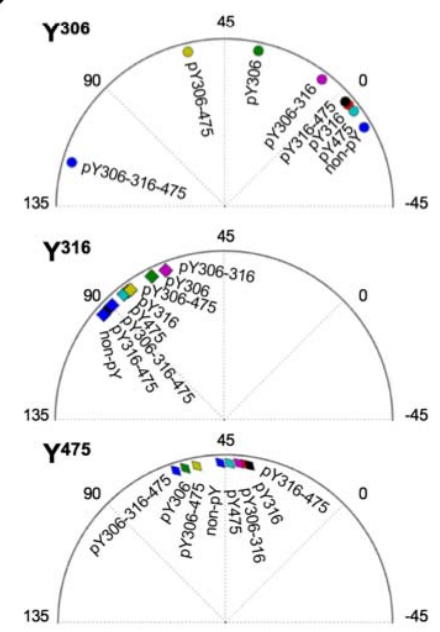

FIGURE 3 

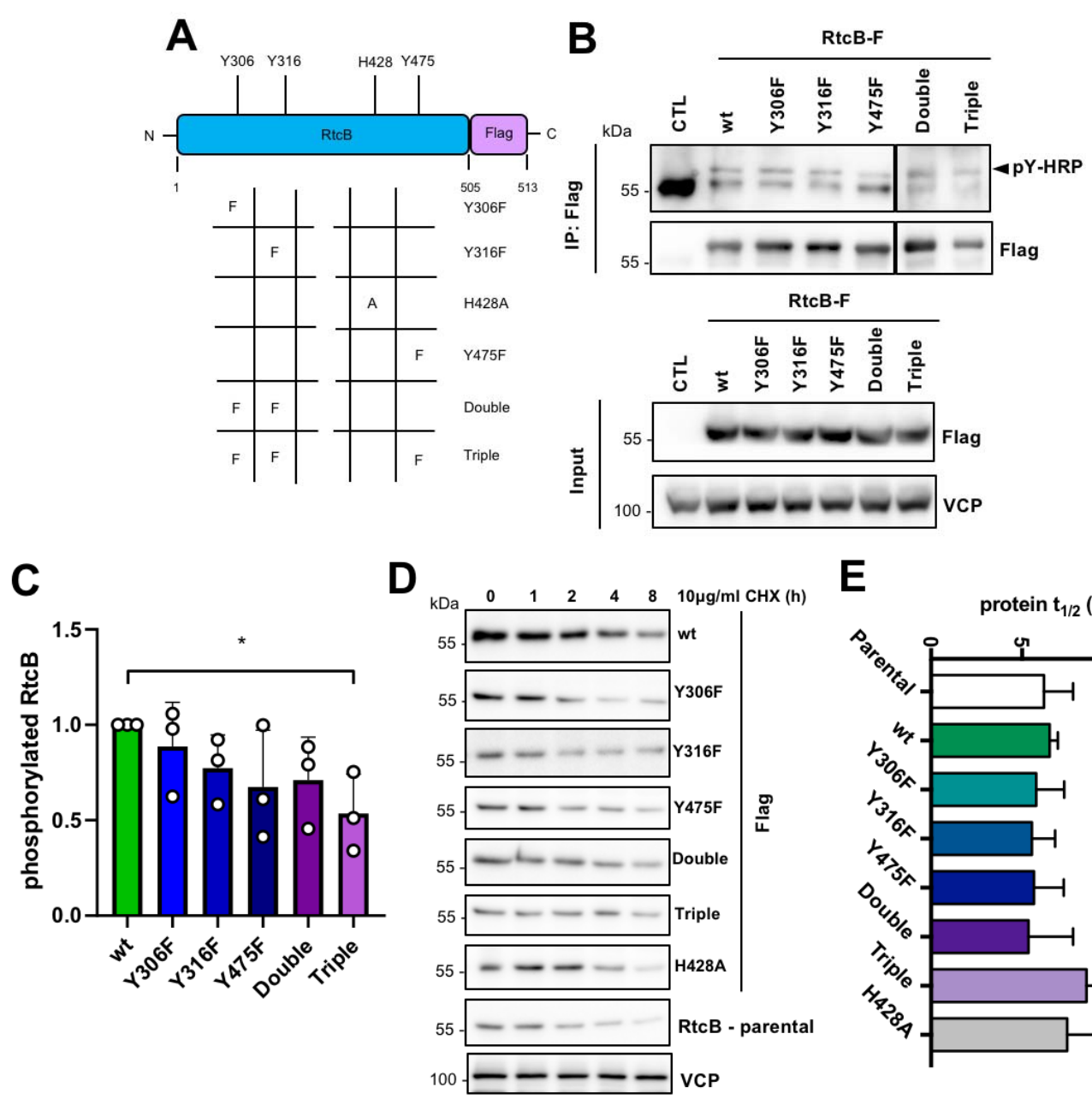

E
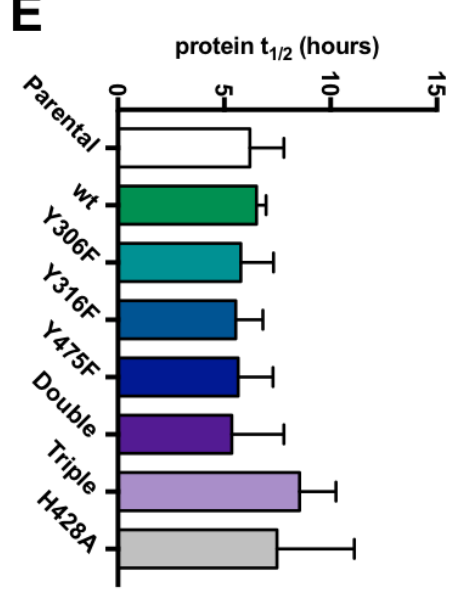

FIGURE 4 
A

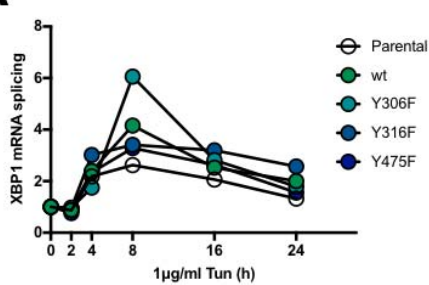

B

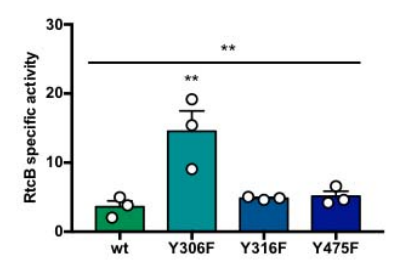

C

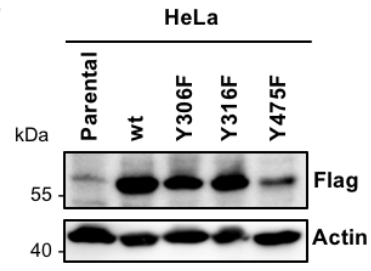

I

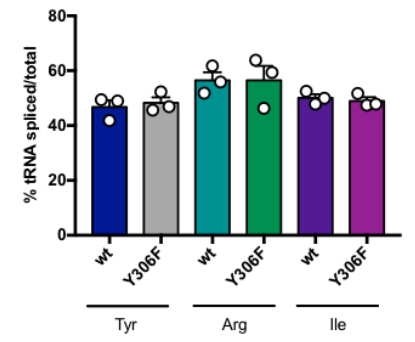

D

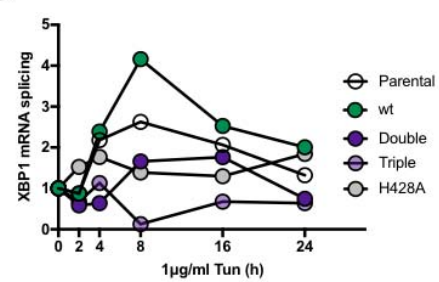

$\mathbf{E}$

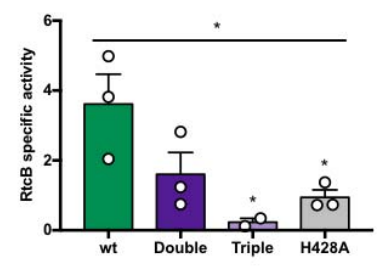

$\mathbf{F}$
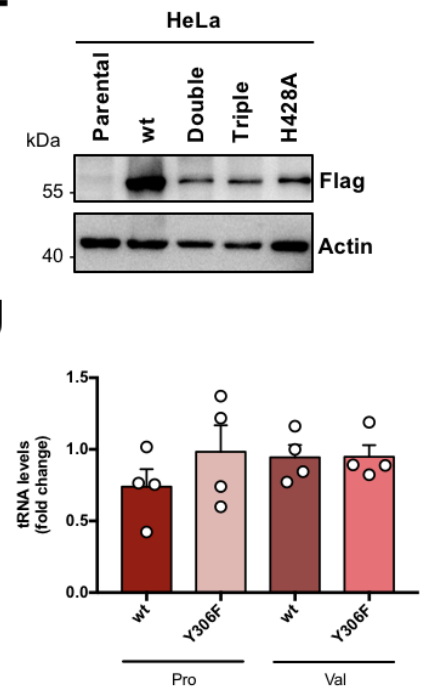

G

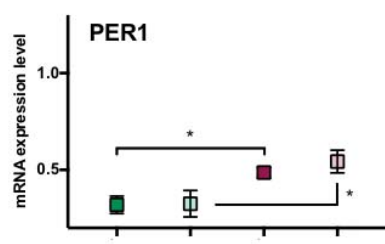

H
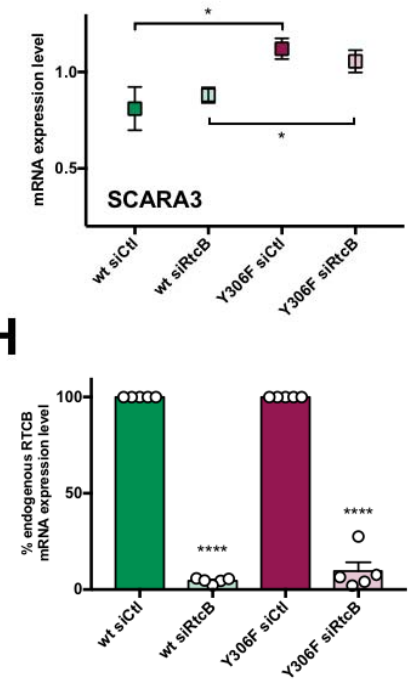

FIGURE 5 
A

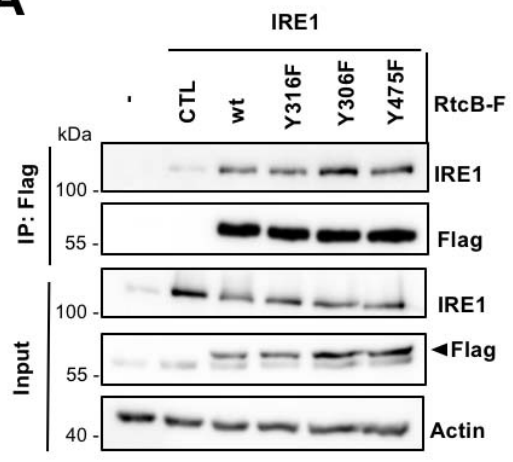

C

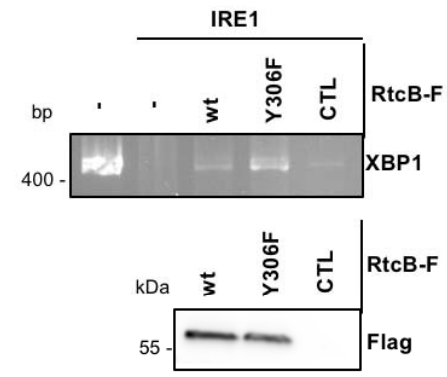

E

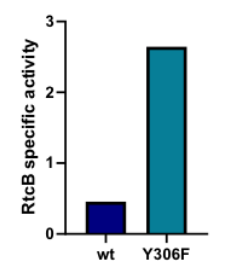

B
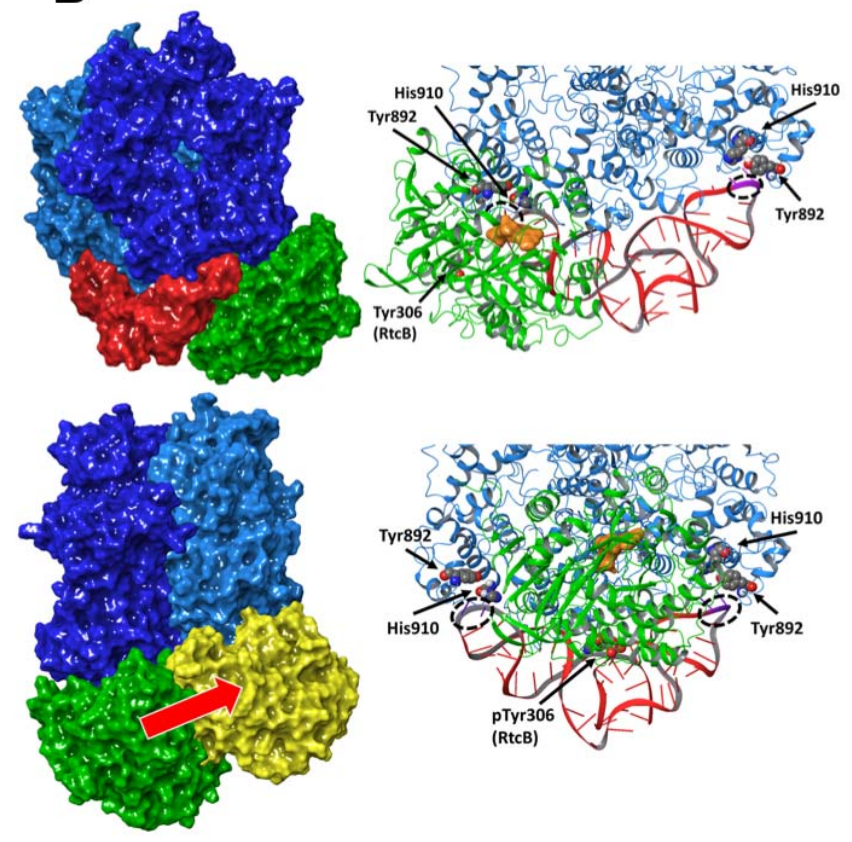

F

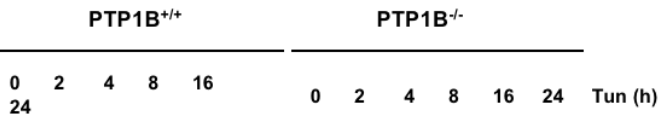

CTL
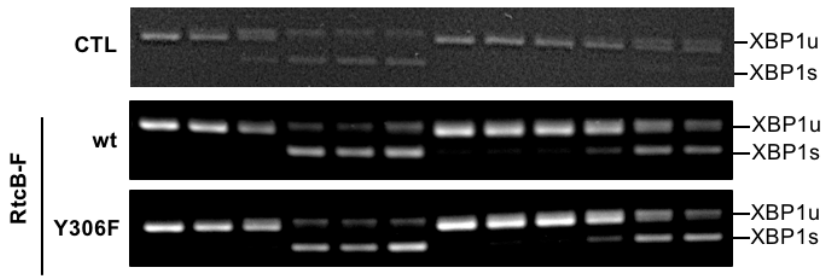

G
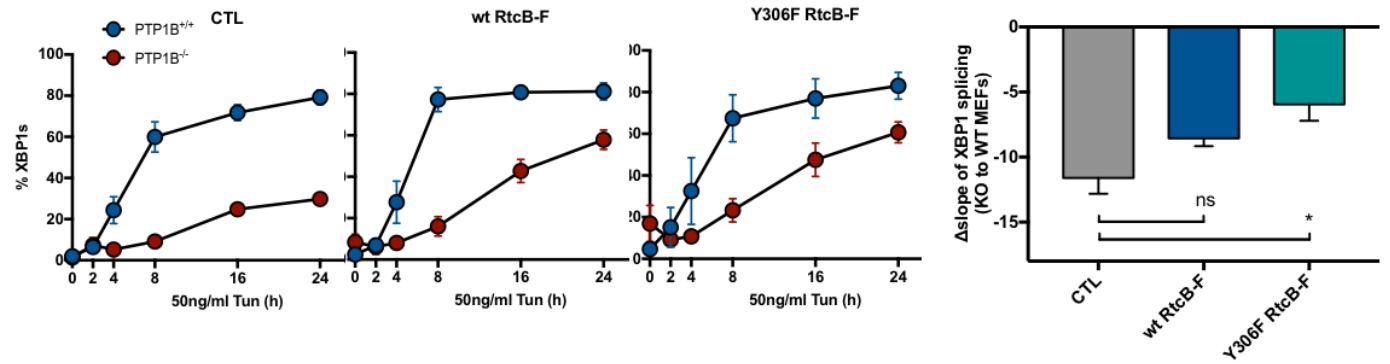

FIGURE 6 


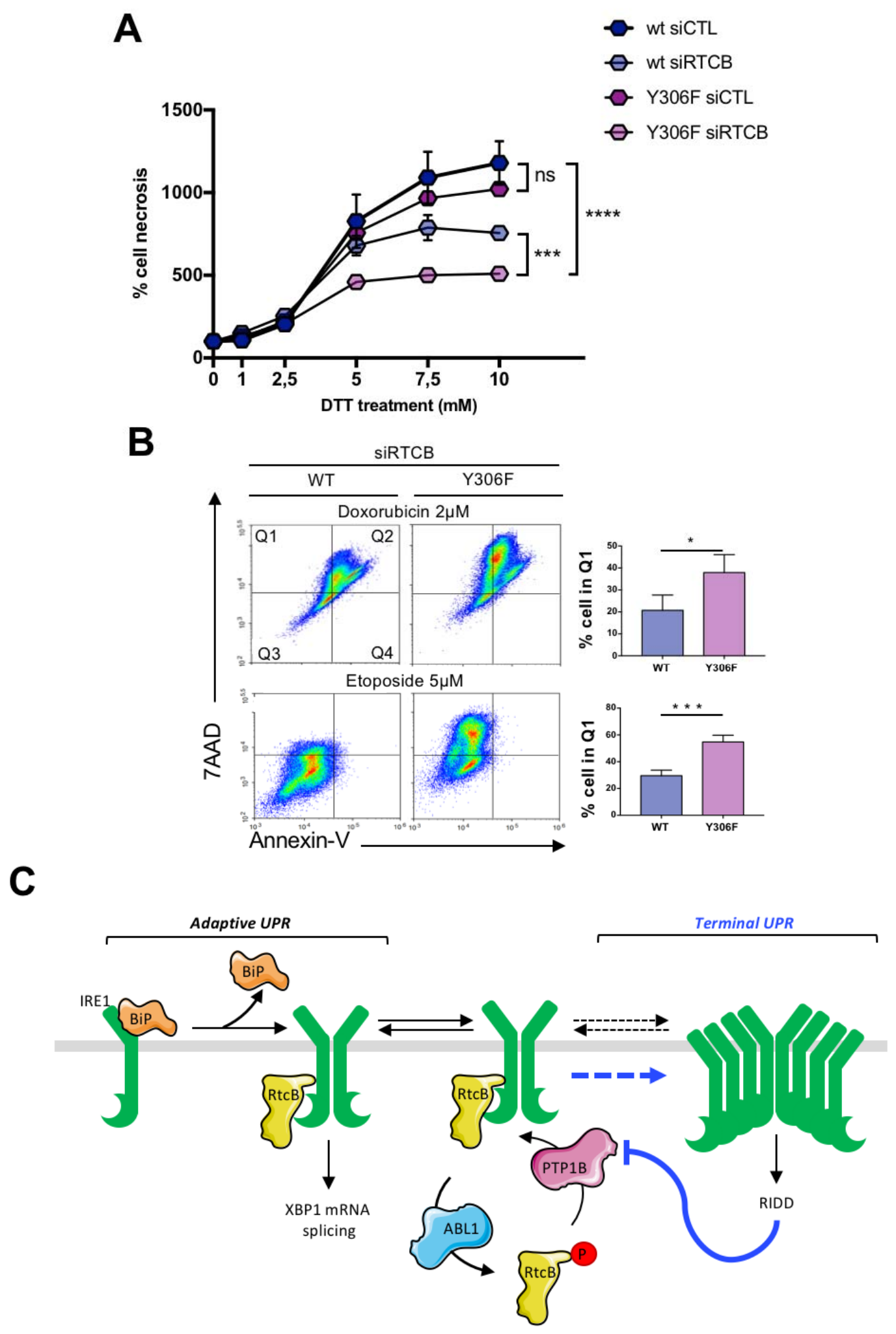

FIGURE 7 